Article

\title{
Experimental and Numerical Investigation of Resonance Characteristics of Novel Pumping Element Driven by Two Piezoelectric Bimorphs
}

\author{
Yu-Chih Lin ${ }^{1}$, Yu-Hsi Huang ${ }^{2, *(D)}$ and Kwen-Wei Chu ${ }^{3}$ \\ 1 Department of Mechanical and Mechatronic Engineering, National Taiwan Ocean University, Keelung 20224, \\ Taiwan; beatrice@mail.ntou.edu.tw \\ 2 Department of Mechanical Engineering, National Taiwan University, Taipei 10617, Taiwan \\ 3 Department of Mechanical Engineering, National Taiwan University of Science and Technology, Taipei \\ 10607, Taiwan; iverson200403@hotmail.com \\ * Correspondence: yuhsih@ntu.edu.tw; Tel.: +886-233662690
}

Received: 11 March 2019; Accepted: 21 March 2019; Published: 24 March 2019

check for updates

Featured Application: This investigation is to establish the model of solid-liquid coupled vibration for piezoelectric material. The experimental measurements and finite element computation results are in good agreement for both the anti-phase and in-phase vibrations coupled with various fluids. The outcome could be featured in pumping-element application that is operated efficiently in resonance.

\begin{abstract}
This paper describes the vibration characteristics of a dual-bimorph piezoelectric pumping element under fluid-structure coupling. Unlike the single bimorph used in most previous studies, the proposed device comprises two piezoelectric bimorphs within an acrylic housing. Amplitude-fluctuation electronic speckle pattern interferometry (AF-ESPI) was used to examine the visible displacement fringes in order to elucidate the anti-phase as well as in-phase motions associated with vibration. Analysis was also conducted using impedance analysis and laser Doppler vibrometer (LDV) based on the measurement of point-wise displacement. The experimental results of resonant frequencies and the corresponding mode shapes are in good agreement with those obtained using finite element analysis. The gain of flow rate obtained by the anti-phase motion of the dual-bimorph pumping element is larger than both those obtained by in-phase motion and the single bimorph pumping element. This work greatly enhances our understanding of the vibration characteristics of piezoelectric pumping elements with two bimorphs, and provides a valuable reference for the further development of bionic pump designs.
\end{abstract}

Keywords: piezoceramic pump; piezoelectric bimorph; solid-liquid coupled vibration; amplitude-fluctuation electronic speckle pattern interferometry (AF-ESPI); laser Doppler vibrometer (LDV); impedance analysis

\section{Introduction}

Due to the characteristics of interchanging the electric field with the mechanical field, the piezoelectric materials are often used as parts of the sensors or actuators. As the micro-fluid techniques develop with the design evolution of the micro-system, the piezoelectric materials are also used for micro-fluid element design. One of the common applications is the pumps being used in micro-fluidic systems in which the vibrating piezoelectric plate is used as the driving element.

The vibration characteristics of piezoelectric plates have been investigated in many research studies. Tiersten [1] proposed a complete liner piezoelectric model, and then derived the constitutive 
equations of the piezoelectric plates' vibration by using the electroelastic equations and the calculus of variations. Tzou [2] analyzed the vibration of piezoelectric shells, and discussed the static and dynamic characteristics of the smart materials made by bonding the piezoelectric layer on other structures. Kunkel et al. [3] investigated the vibration modes of PZT-5H ceramics disks in different diameter-to-thickness ratios. Guo et al. [4] determined the PZT-5A piezoelectric disks' vibration with 20 and 10 diameter-to-thickness ratios. The symmetric modes of vibration for circular piezoelectric plates was studied by Ivina [5] in order to optimize the dynamic electromechanical coupling coefficient. Most of the above-mentioned research studies that have analyzed the vibration of piezoelectric plates contain analytical and numerical results. The experimental results are needed to verify the theoretical computation.

Numerous researchers have investigated the vibrations in the piezoelectric elements used in micropumps. Wu and $\mathrm{Lu}[6]$ used a mathematical algorithm and FEM analysis to derive the vibration characteristics of a circular Si thin film used in a piezoelectric micropump affected by solid-fluid coupling. They determined that the natural frequency in a coupled system is far lower than that in a non-coupled system. With a focus on flow rates, De Lima et al. [7] implemented a valveless micropump in acrylic in which the vibration of a piezoelectric plate mimicked the caudal fins of a fish. Zhou [8] employed mathematical computation and finite element analysis to describe the vibrations in a micropump model with a focus on the means by which geometrical dimensions and fluid properties affect the resonant frequency. Hou et al. in 2008 [9] examined the vibration characteristics of a micropump with a diaphragm bonded to a piezoelectric element. Ma et al. [10,11] developed a novel micropump that drives fluid via the vibration of a diaphragm. When implemented in the cooling system of a laptop computer, this device proved to be highly stable, thanks to its high flow rate. Ma et al. [12] also developed an innovative one-sided actuating piezoelectric valveless micropump (OAPMP-valveless) that uses a secondary chamber to pump the fluid at higher flow rates. Then, experiments were conducted on the valveless micropump to verify the efficacy of the underlying three-dimensional (3D) numerical model. The fish-tailing type of valveless piezoelectric pump was also proposed in the study of Huang el. al [13]. The dynamic analysis was performed theoretically; then, the flow rates under different driving frequencies were also studied through the experiment by Huang et al. [14]. Then, Singh et al. [15] presented the analytical and simulating model of a piezoelectric plate (PZT) actuated planar valveless PDMS micropump. The pump included a taper at the outlet to improve the flow rate, and the significant improvement of $28 \%$ was indicated in the research. The effect of the frequency and voltage on the flow rate and pressure-flow characteristics were also studied through the experiments.

The full-field optical measurement technique referred to as amplitude-fluctuation electronic speckle pattern interferometry (AF-ESPI) is highly effective in determining the resonant frequencies and corresponding vibration mode shapes of piezoelectric materials. Ma and Huang [16,17] employed the AF-ESPI method to investigate the vibration characteristics of piezoelectric cylinders and rectangular parallelepipeds in order to obtain the resonant frequencies and mode shapes. Huang et al. [18] used three experimental techniques, including AF-ESPI, laser Doppler vibrometry (LDV), and impedance analysis to validate a theoretical analysis model derived for piezoceramic disks under stress-free boundary conditions. They also used theoretical analysis, numerical simulation, and experimental measurements to assess the vibration characteristics for piezoceramic annular disks. Lin and Ma [19] used AF-ESPI and numerical analysis to investigate the out-of-plane resonant characteristics of a cantilevered piezoceramic plate in air and three types of fluid. Both experimental and theoretical measurements revealed that the resonant frequencies decreased with an increase in the viscosity of the fluids.

A number of researchers have studied the characteristics of micropumps equipped with a single bimorph; however, there has been relatively little research on the vibration of pumping elements equipped with two bimorphs. In this study, we developed a pumping element that uses two cantilevered piezoelectric bimorphs rather than a single bimorph in order to increase the flow rate. 
Then, we used AF-ESPI, LDV, and impedance analysis to investigate the vibration characteristics of two piezoelectric plates coupled to bounded compressible inviscid fluids. Finally, we formulated a numerical model using the commercial software ABAQUS v6.13.2 [20] to facilitate a comparison of the results. The gain of flow rate and the flow velocity increment of the pumping element were also investigated through the experiment. Our findings provide a novel perspective for the further development of piezoelectric pumping elements driven by two bimorphs.

\section{Specimens and Experiment Setup}

\subsection{Materials and Specimens}

The structure of the pump housing was fabricated from acrylic, due to its low cost and ease of shaping. Two rectangular bimorphs were attached to this structure under one-edge-fixed boundary conditions. The piezoceramic bimorph used in the experiments was a triple-layer structure with the following dimensions: $63.5 \mathrm{~mm} \times 31.8 \mathrm{~mm} \times 0.48 \mathrm{~mm}$ (Q220-A4-503YB, Piezo System Inc., Cambridge, MA, USA), as detailed in Figure 1. After it was clamped into the pumping element structure, the effective length of the bimorph was reduced to $55 \mathrm{~mm}$, as shown in Figure 2a-d. Table 1 lists the material properties of the piezoceramic plate (PSI-5A4E, Piezo System Inc., MA, USA) bonded to the outer layer of the bimorph, and those of the brass in the middle layer. Figure 3 presents images of the pumping unit.

Table 1. Material properties of piezoelectric bimorph.

\begin{tabular}{|c|c|c|}
\hline Material Properties & Structural Plate (Brass) & Piezoelectric Plate (PZT) \\
\hline Model Name & Bronze C86100 & PSI 5A4E \\
\hline Density & $8830 \mathrm{~kg} / \mathrm{m}^{3}$ & $7800 \mathrm{~kg} / \mathrm{m}^{3}$ \\
\hline Young's Modulus & $1.03 \times 10^{11} \mathrm{~Pa}$ & $\begin{array}{l}x \text {-direction- } 6.6 \times 10^{10} \mathrm{~Pa} \\
y \text {-direction- } 6.6 \times 10^{10} \mathrm{~Pa} \\
z \text {-direction- } 5.2 \times 10^{10} \mathrm{~Pa}\end{array}$ \\
\hline Poisson's Ratio & 0.34 & $\begin{array}{c}x \text {-direction- } 0.31 \\
y \text {-direction- } 0.242 \\
z \text {-direction- } 0.242\end{array}$ \\
\hline Piezoelectric Constants & - & $\begin{array}{l}d_{15}=550 \mathrm{pm} / \mathrm{V} \\
d_{31}=-190 \mathrm{pm} / \mathrm{V} \\
d_{33}=390 \mathrm{pm} / \mathrm{V}\end{array}$ \\
\hline Dielectric Constants & - & $\begin{array}{l}\varepsilon^{S}{ }_{11}=11.12 \mathrm{nF} / \mathrm{m} \\
\varepsilon^{S}{ }_{33}=14.02 \mathrm{nF} / \mathrm{m}\end{array}$ \\
\hline
\end{tabular}

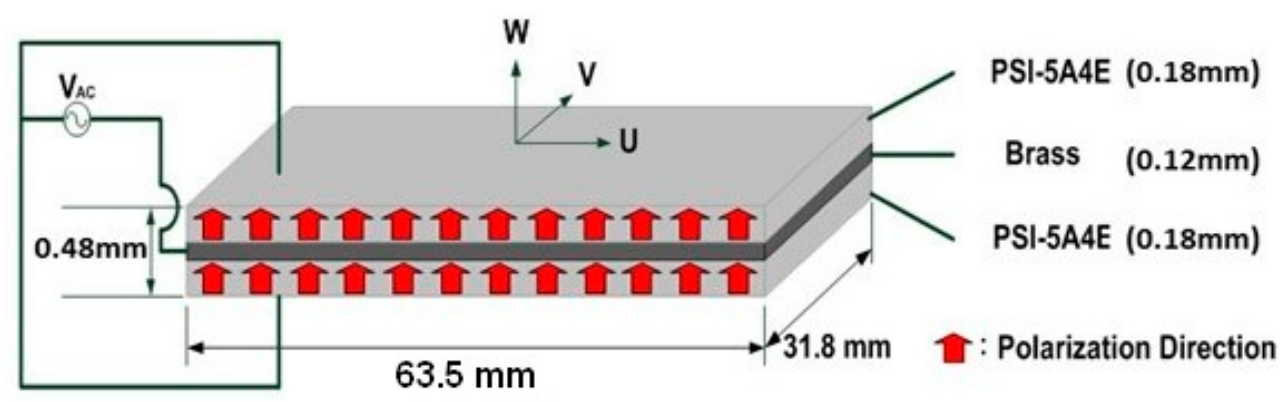

Figure 1. Schematic illustration showing the geometric dimensions of the piezoceramic bimorph in a parallel connection configuration. 


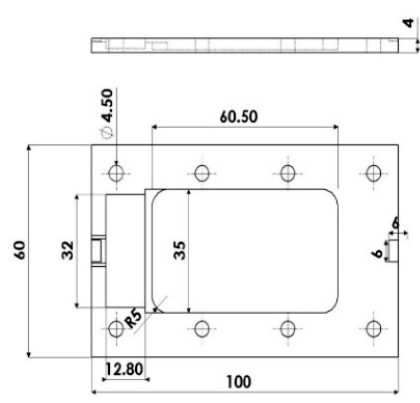

(a)
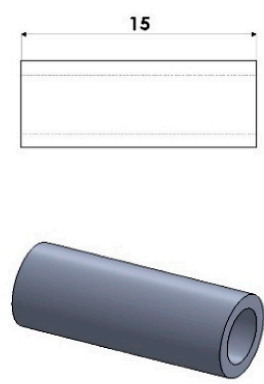

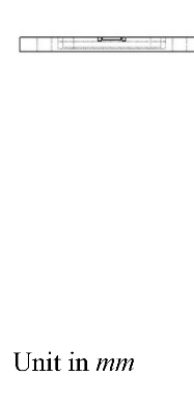

nnit in $\mathrm{mm}$

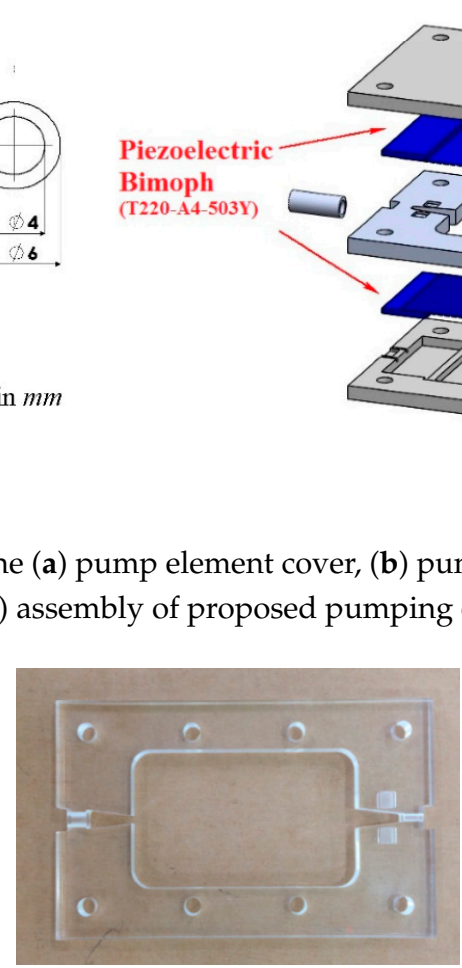

(b)

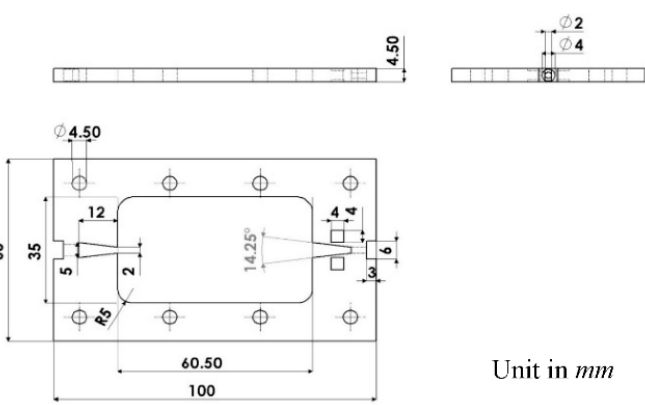

(b)

(c)

(d)

Figure 2. Engineering draft of the (a) pump element cover, (b) pump element chamber, (c) dimensions of inlet and outlet pipes, and (d) assembly of proposed pumping element.

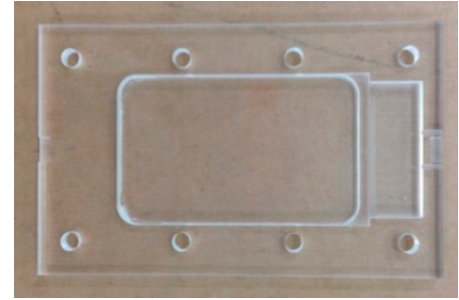

(a)

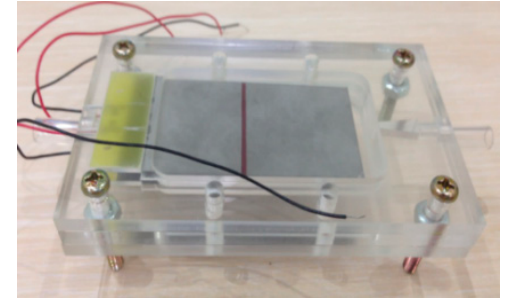

(c)

Figure 3. Photographic images of pumping element: (a) outer cover, (b) middle chamber, and (c) assembled unit.

\subsection{Amplitude-Fluctuation Electronic Speckle Pattern Interferometry (AF-ESPI)}

The full-field optical measurement technique referred to as amplitude-fluctuation electronic speckle pattern interferometry (AF-ESPI) is highly effective in determining the resonant frequencies and the corresponding vibration mode shapes of piezoelectric materials. We considered only out-of-plane displacement, since the displacement associated with in-plane motion is relatively small. The out-of-plane layout of the upper plate in Figure 4a,b shows that the laser beam was split into two parts using a variable beam splitter. One of the laser beams served as an objective light directed toward the specimen to be reflected to the CCD camera. The other laser beam was used to illuminate the surface of a plate to create a speckled reference light, which was also reflected into a CCD camera. The object and reference beams were then joined in CCD sensor array. Details of the AF-ESPI experiment procedure for out-of-plane vibrations can be found in $[15,16]$. In this study, we measured the mode shapes and resonant frequencies of the upper and lower bimorphs. This required a special layout that included a reflector to capture images of the lower bimorph, as shown in Figure 4c,d. Unlike previous studies, this approach has the lower bimorph located in a position that is difficult to access (below the upper bimorph); hence, a reflection mirror is used for obtaining the image of the lower bimorph. 


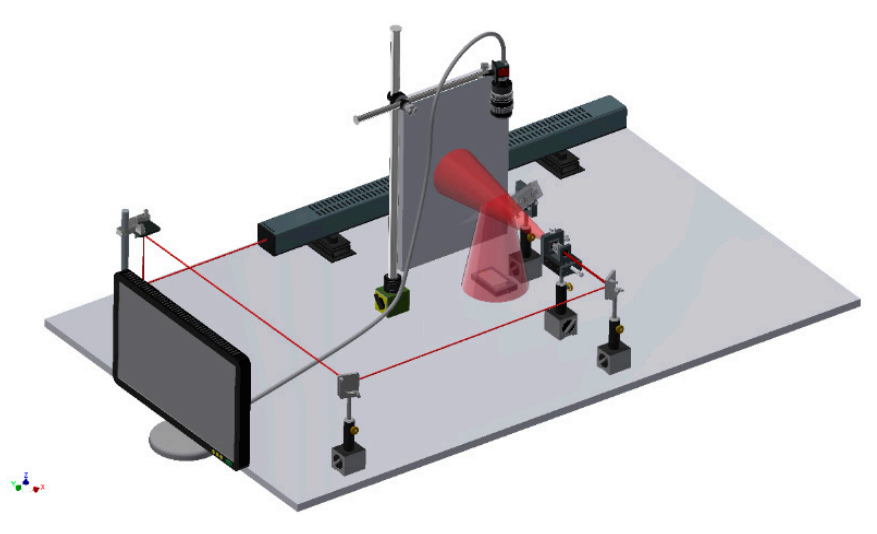

(a)

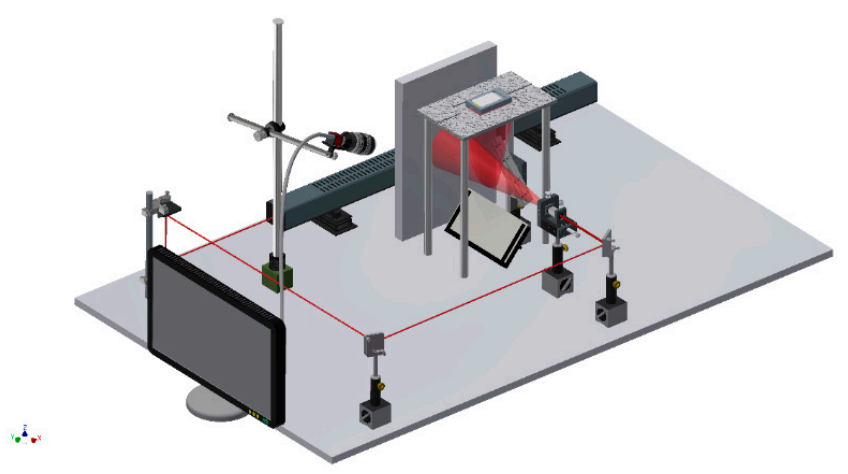

(c)

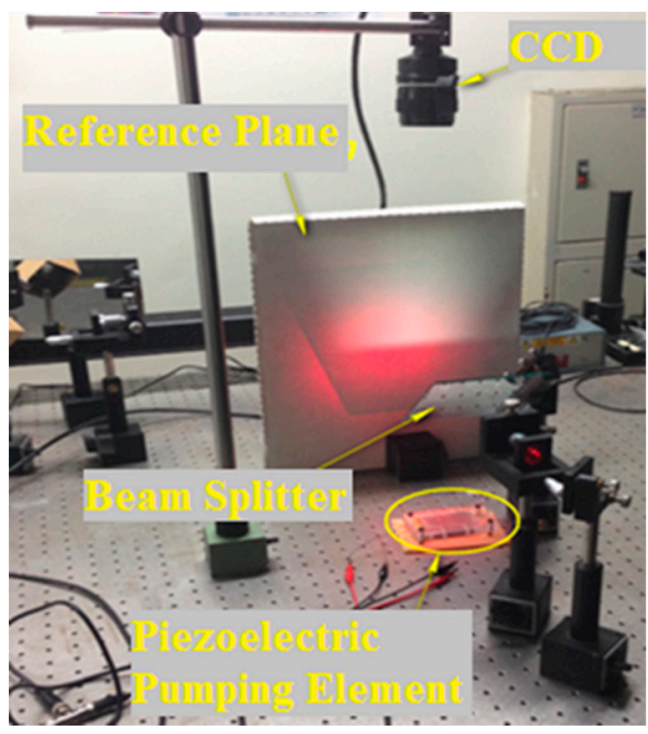

(b)

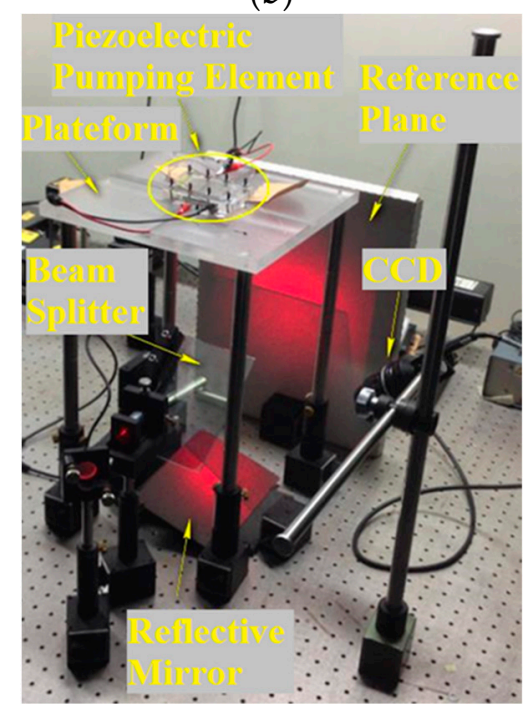

(d)

Figure 4. Schematic diagrams and implementations showing set-up of the amplitude-fluctuation electronic speckle pattern interferometry (AF-ESPI) experiment for out-of-plane measurements of upper and lower bimorphs: (a) the schematic diagram for the upper bimorph, (b) the implementation for the upper bimorph, (c) the schematic diagram for the lower bimorph, and (d) the implementation for the lower bimorph.

\subsection{Laser Doppler Vibrometer (LDV)}

We employed a laser Doppler vibrometer (LDV) (PDV-100, Polytec GmbH, Waldbronn, Germany) to obtain point-wise displacement measurements to be compared with the results of ESPI. This device is designed for non-contact measurement at vibration frequencies of up to $22 \mathrm{kHz}$, based on the principles underlying the Michelson interferometer and Doppler effect. This type of interferometer generates a high-frequency carrier signal within the photo detector using an acousto-optical modulator (Bragg cell). A helium neon laser beam applied to the specimen is scattered back, allowing the measurement of vibration speeds based on the difference in frequency between the two light beams. The working distance of this device ranges from $0.1 \mathrm{~m}$ to $30 \mathrm{~m}$, and the laser spot is $30 \mu \mathrm{m}$ in diameter (based on a focal length of $0.234 \mathrm{~m}$ ). In this study, the focal length was varied between $0.15-0.5 \mathrm{~m}$, resulting in a maximum laser spot of $124 \mu \mathrm{m}$. Velocity is the original data measured using an LDV; however, displacement and acceleration can both be derived via computation. In this study, a swept-sine signal 
generated by a function generator (controlled by MATLAB) was input to excite the piezoelectric bimorphs. A computer was used to record the velocity values measured using the LDV system when the bimorph is stimulated by a converse piezoelectric effect. The peaks that appeared as local maxima in the response curve indicate the resonant frequencies of the specimens under transverse vibration. This LDV system enables accurate vibration analysis; however, it is not conducive to deriving full-field resonance characteristics.

\subsection{Impedance Analysis}

Impedance is an important property of piezoelectric elements. The resonant frequency $\left(f_{r}\right)$ and anti-resonant frequency $\left(f_{a}\right)$ correspond to the local minimum and the local maximum of the frequency-impedance curve. They are derived using impedance analysis with the electromechanical coupling coefficient represented as follows:

$$
k_{d}=\sqrt{\frac{f_{a}^{2}-f_{r}^{2}}{f_{a}^{2}}}
$$

We obtained the impedance response curves of the piezoelectric bimorphs using an impedance analyzer (E4990A, Keysight Technologies) with a measurement range of $20 \mathrm{~Hz}$ to $10 \mathrm{MHz}$. Zhou et al. [21] proposed an electromechanical model related to impedance and velocity to demonstrate the vibration characteristics of piezoelectric components. That model was subsequently used by Bhalla and Soh [22,23] in the development of a piezoelectric transducer. The results of impedance analysis were later compared with the optical measurements.

\subsection{Finite Element Analysis}

We employed the commercial finite element software package ABAQUS v6.13.2 (Hibbit, Karlsson, and Sorensen, Inc., Pawtucket, RI, USA) to analyze the problem of solid-fluid coupling. A 20-node three-dimensional (3D) solid piezoelectric element (C3D20RE) was used to simulate piezoceramic materials, whereas a 20-node 3D solid element (C3D20R) was used for the simulation of brass. Each layer included 448 elements and 3359 nodes, and a surface-based tie constraint was used for the solid-fluid interface. The frequency range of the resonant analysis was 1 to $6000 \mathrm{~Hz}$. It was assumed that the direction of bimorph polarization was parallel, as indicated in Figure 1. The upper and lower electrode surfaces of the two piezoceramic plates and the middle brass layer were assumed to be conductive regions.

Table 2 lists the material properties of the fluids used for acoustic coupling analysis in this study, including air, water, and glycerine. The acoustic coupling element (AC3D20) was used for fluid simulation. Figure 5 presents the full model used in the analysis of structure-fluid interactions. It was assumed that the material was elastic, compressible, non-viscous, and capable of bearing hydrostatic stress, which was proportional to the volume strain, as follows:

$$
\sigma=K_{f} \varepsilon_{V}
$$

where $K_{f}$ is the bulk modulus, $\varepsilon_{V}=\varepsilon_{11}+\varepsilon_{22}+\varepsilon_{33}$.

Table 2. Material properties of fluids.

\begin{tabular}{cccc}
\hline Material Constants & Air & Water & Glycerine \\
\hline Bulk Modulus & $1.42 \times 10^{6} \mathrm{~N} / \mathrm{m}^{2}$ & $2.2 \times 10^{9} \mathrm{~N} / \mathrm{m}^{2}$ & $4.39 \times 10^{9} \mathrm{~N} / \mathrm{m}^{2}$ \\
Density & $1.2 \mathrm{Kg} / \mathrm{m}^{3}$ & $1000 \mathrm{Kg} / \mathrm{m}^{3}$ & $1260 \mathrm{Kg} / \mathrm{m}^{3}$ \\
Wave Velocity & $344 \mathrm{~m} / \mathrm{s}$ & $1483 \mathrm{~m} / \mathrm{s}$ & $1875 \mathrm{~m} / \mathrm{s}$ \\
Viscosity & $0.00001 \mathrm{~Pa} \cdot \mathrm{s}$ & $0.001 \mathrm{~Pa} \cdot \mathrm{s}$ & $1.2 \mathrm{~Pa} \cdot \mathrm{s}$ \\
\hline
\end{tabular}




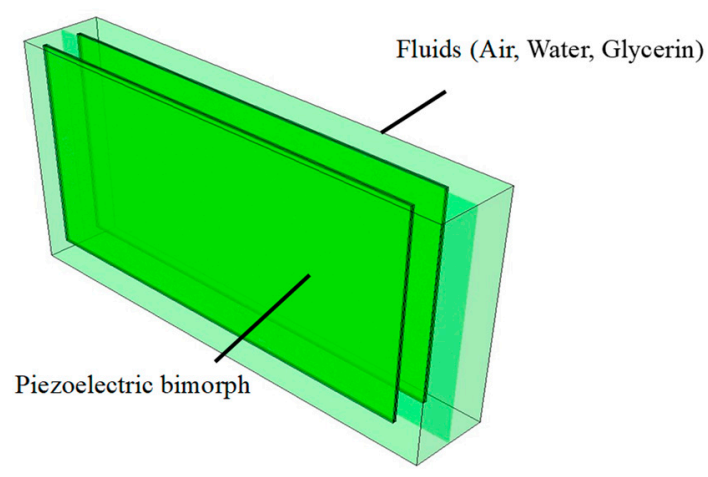

(a)

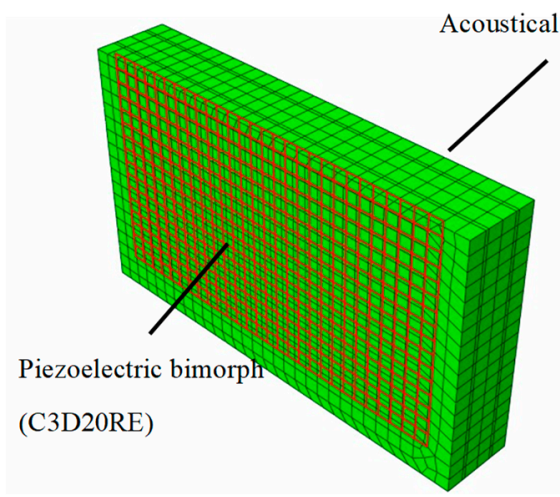

(b)

Figure 5. Finite element model of proposed piezoelectric pumping element: (a) immersed region as shown in transparent, and (b) element types.

The equilibrium equation is as follows:

$$
\frac{\partial p}{\partial x}+\gamma \dot{u}^{f}+\rho_{f} \ddot{u}^{f}=0
$$

where $p$ is the pressure above the static pressure, $x$ is the spatial position of a fluid particle, $\dot{u}^{f}$ is the velocity of the fluid particle, $\ddot{u}^{f}$ is the acceleration of the fluid particle, $\rho_{f}$ is the density of the fluid, and $\gamma$ is the volumetric drag. In this acoustic analysis, we assumed a steady-state configuration, which means that only the bulk modulus and density have an impact on computation; i.e., volumetric drag is disregarded.

\subsection{The Flow Rate and Flow Velocity Measurement}

To verify the pumping efficiency of the anti-phase and in-phase motion of the two-bimorph structure, the experiment set-up is designed as shown in Figure 6. Figure 6a shows the flow rate testing layout. A flow induced by water level is designed with the bionic piezoelectric valveless pump. The silicone tube straight alignment must be confirmed in order to avoid the resistance caused by flow in the bending tube. The water is poured into the water tank, so that the water flows naturally into the cavity and discharges the air. A cup placed on the electronic scale is set at the end of the outlet to measure the output water weight. The steady-state flow rate is measured by dividing the water volume by the time it takes to flow through the tube without using the pump. The gain of flow rate is obtained by dividing the flow rate increment when the pump is used by the steady-state flow rate. Figure $6 \mathrm{~b}$ shows the flow velocity testing set-up, which is similar to the flow rate measuring test. The colored droplets are squeezed, and the time the colored liquid flows out of the silicone tube is measured. The flow velocity is computed by dividing the displacement of the tube length by the time it takes to finish flowing through it.

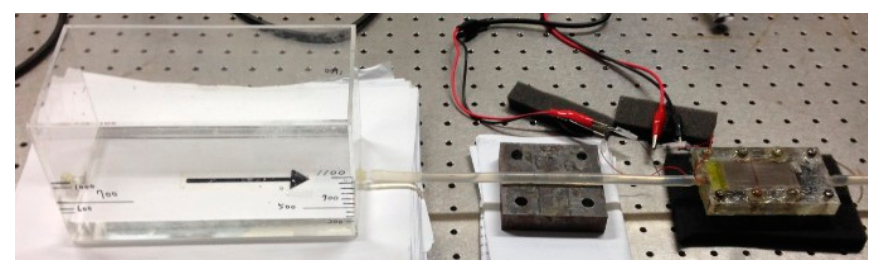

(a)

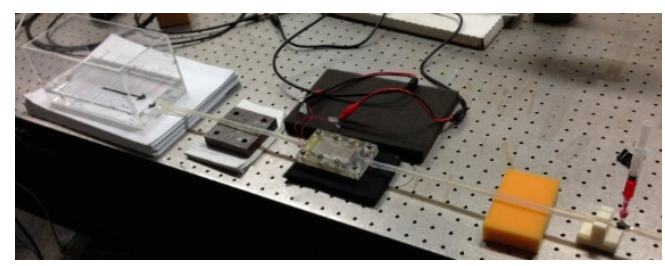

(b)

Figure 6. (a) The flow rate measurement set-up, and (b) the flow velocity measurement set-up of the pumping element. 
Figure 7 shows the electrical connection of dual piezoelectric bimorphs to drive the anti-phase and in-phase motions. The various electrical fields are applied on the upper-layer and lower-layer piezoelectric ceramics with different polarization to produce larger bending deformation, since the shrinkage and extension were caused respectively by the same and the opposite directions between the electrical field and the polarization. The deformation mechanism on the piezoelectric bimorph was discussed in detail by Huang and Ma [24].

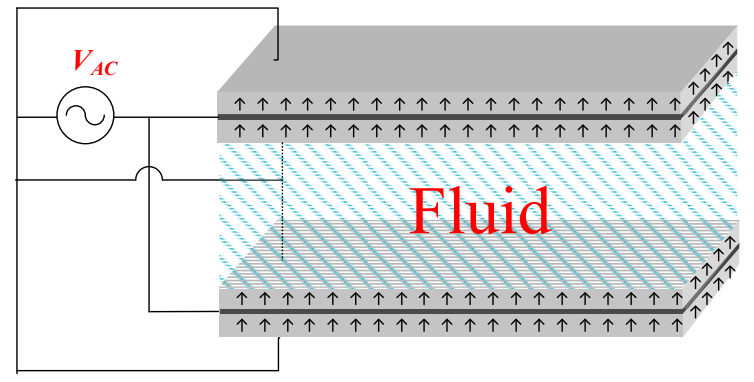

(a)

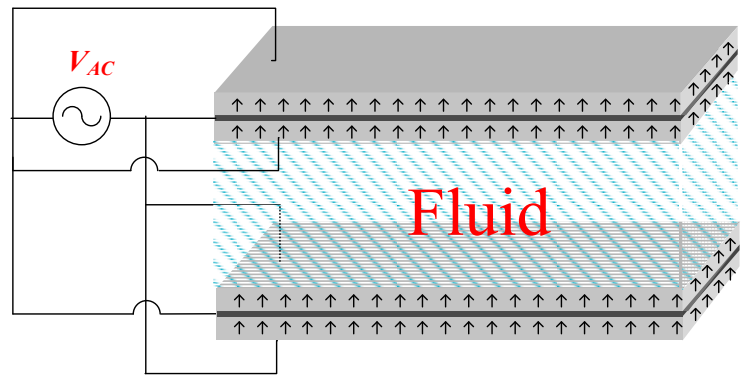

(b)

Figure 7. Configuration in electrical connections of dual piezoelectric bimorphs to drive in (a) anti-phase motion and (b) in-phase motion.

\section{Experimental and Numerical Results}

Figures $8 \mathrm{a}, \mathrm{b}, 9 \mathrm{a}, \mathrm{b}$ and $10 \mathrm{a}, \mathrm{b}$ respectively present the vibration characteristics of a valveless pumping element (operating in air, water and glycerine) under structure-fluid coupling, as derived from AF-ESPI experiments and FEM computation. Tables 3-5 present a detailed comparison of the resonant frequencies obtained using AF-ESPI and numerical analysis. The mode shapes and the corresponding resonant frequencies are presented for anti-phase as well as in-phase motions. The AF-ESPI results clearly show fringes that are indicative of mode shapes. In this case, we measured only out-of-plane motion due to its relatively large displacement, compared to in-plane motion. The brightest fringes represent the nodal lines of the piezoceramic bimorph in resonance. The remaining fringes represent the constant displacement contours. 

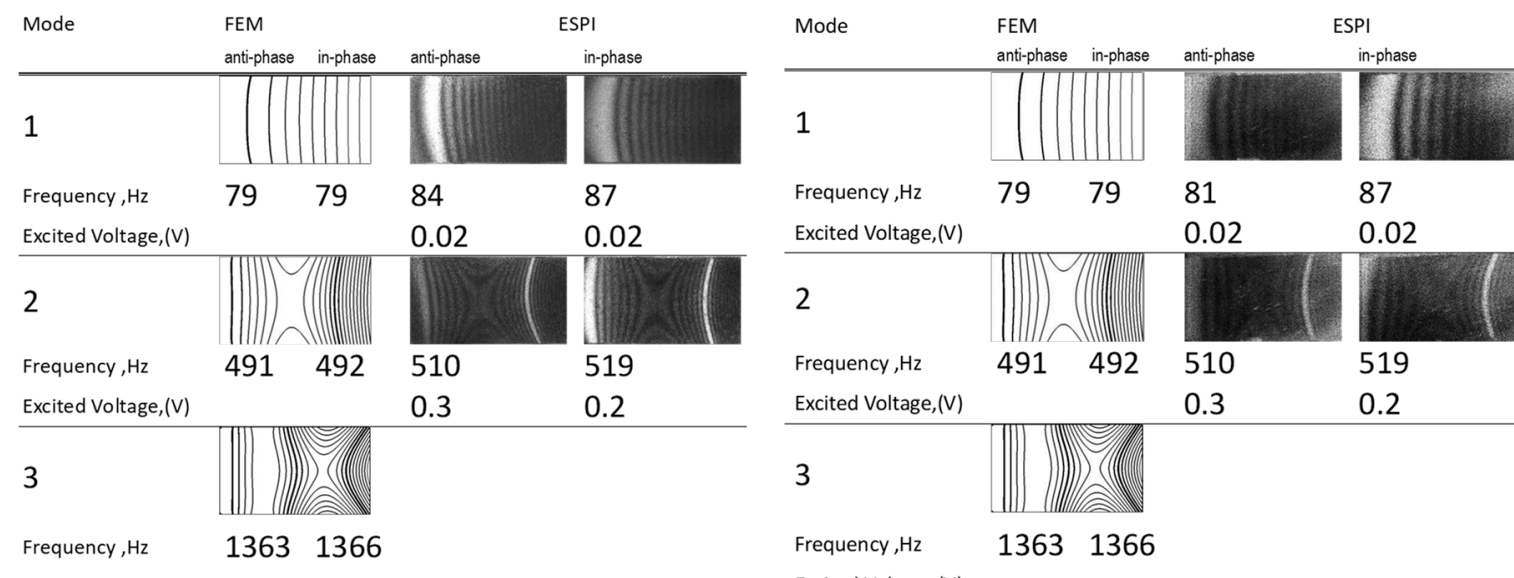

Excited Voltage,(V) $\quad 0.02 \quad 0.02$

2

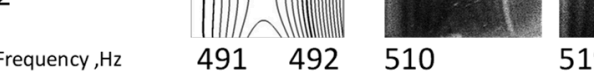

Excited Voltage, $(\mathrm{V}) \quad 0.3 \quad 0.2$

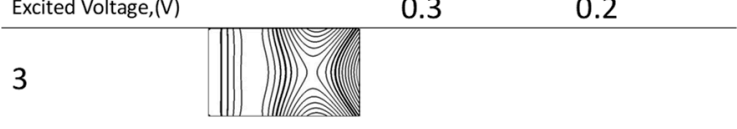

Excited Voltage,(V)

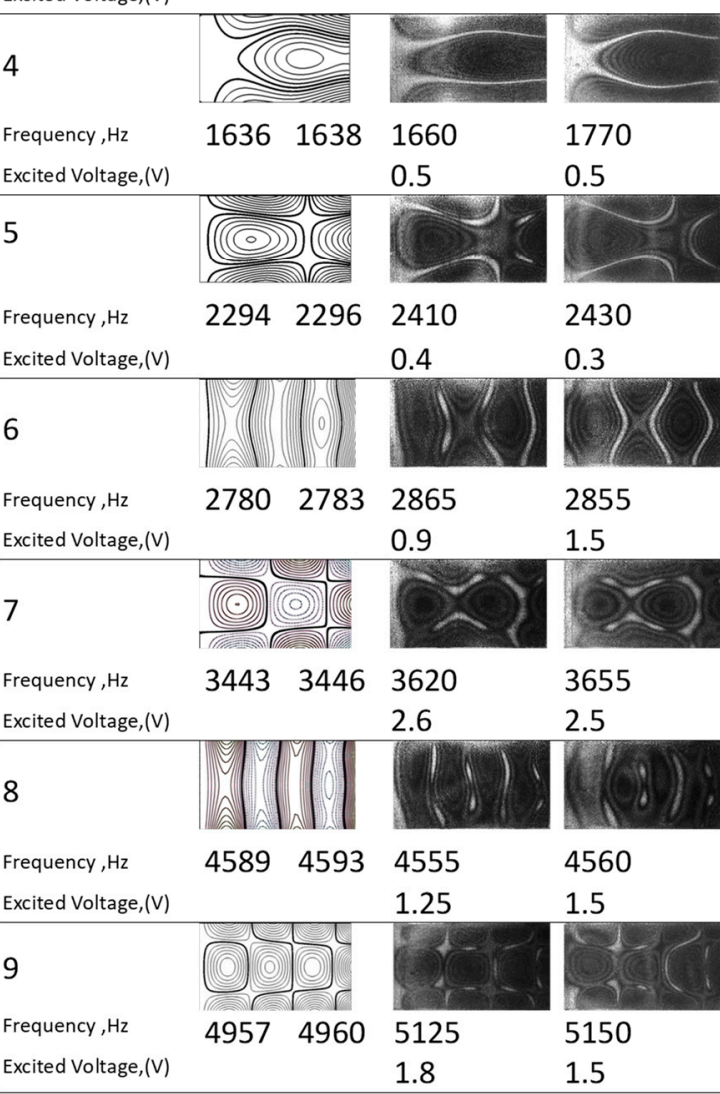

(a)

\section{Frequency, $\mathrm{Hz} \quad 13631366$}

Excited Voltage,(V)

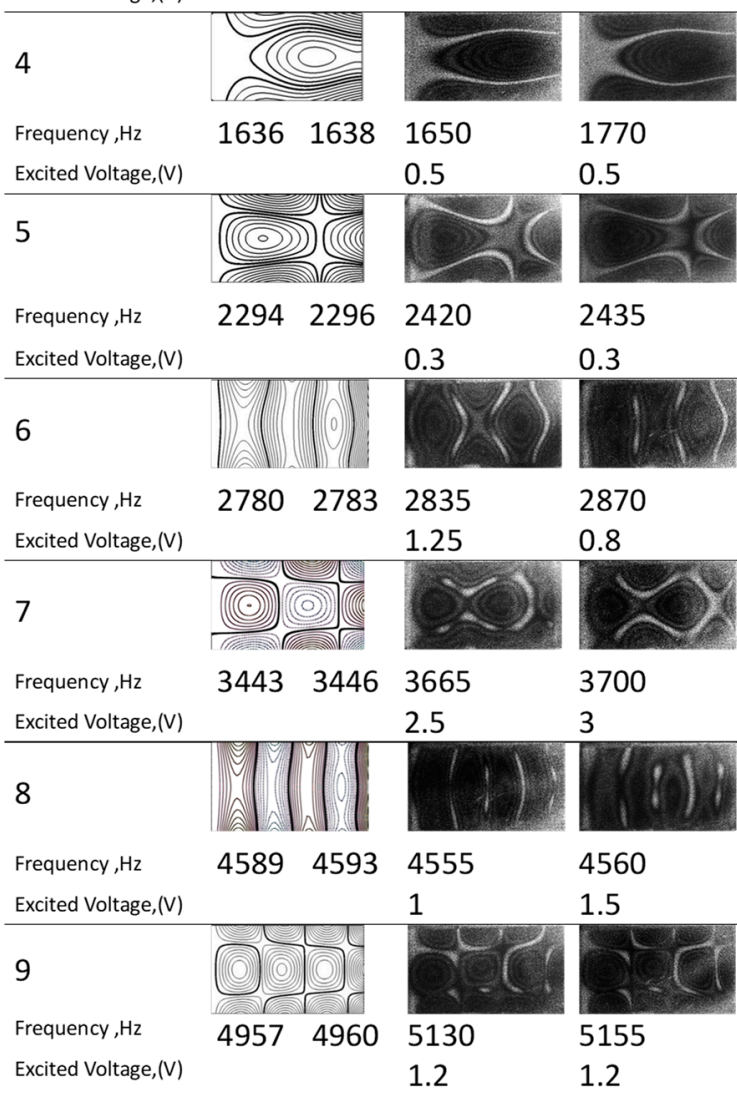

(b)

Figure 8. AF-ESPI and FEM results obtained from pumping element coupled with air (a) upper and (b) lower piezoelectric plate.

The results in Figures 8-10 indicate that the mode shapes of the anti-phase and in-phase motions are similar to the vibrations of a piezoelectric bimorph coupled with air. When the fluid effect was more pronounced (water-coupled and glycerine-coupled cases), the differences between the anti-phase and in-phase mode shapes was more obvious. In the glycerine-coupled case, the anti-phase and in-phase motions differed considerably in terms of mode shape and resonant frequency due to the effects of viscosity. Under all three conditions, the mode shapes and resonant frequencies were similar at low frequencies (both upper and lower plates). The resonant frequencies decreased with density and an increase in the viscosity of the fluid. 


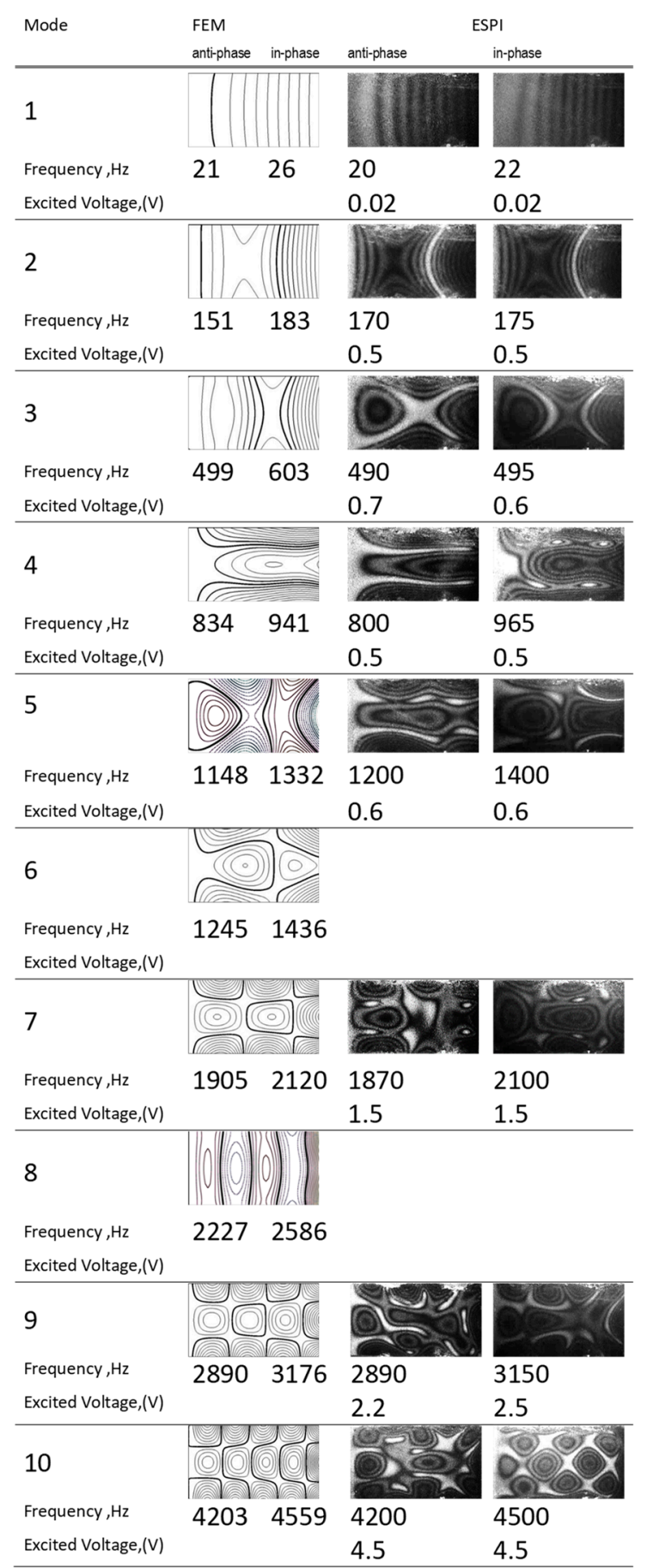

(a)

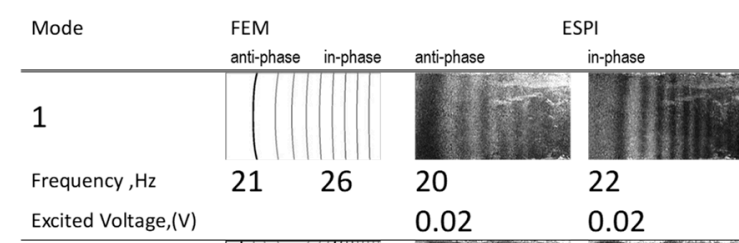

Excited Voltage, (V)

2

Frequency, $\mathrm{Hz}$

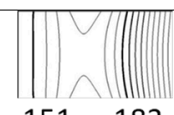

0.02 0.02

Excited Voltage,(V)
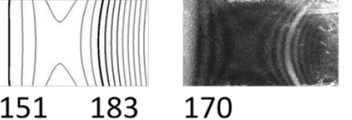

170
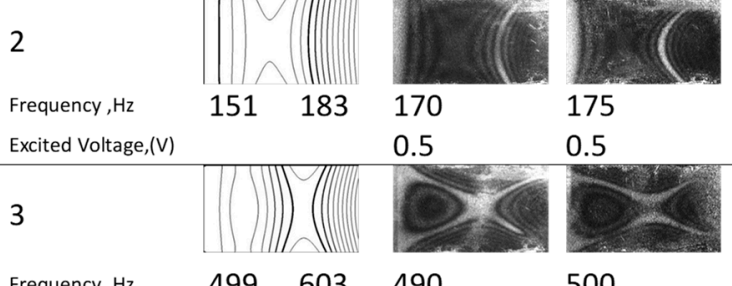

0.5

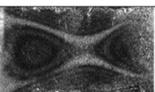

Frequency, $\mathrm{Hz}$

Excited Voltage,(V)

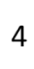

4

0.7

500

0.6

Frequency, $\mathrm{Hz}$
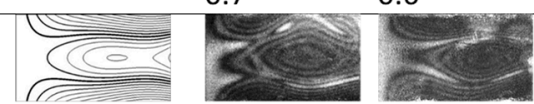

Excited Voltage,(V)

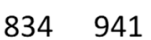

900

965

5

5

0.5

0.5

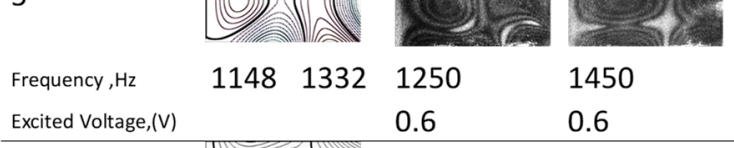

Excited Voltage,(V)

6

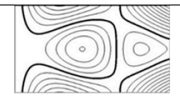

Frequency, $\mathrm{Hz} \quad 12451436$

Excited Voltage,(V)
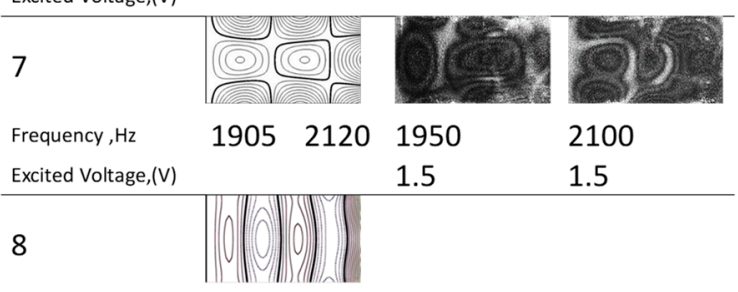

Frequency, $\mathrm{Hz}$

22272586

Excited Voltage,(V)
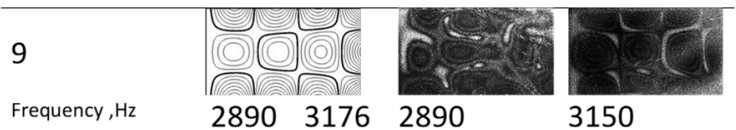

Frequency, $\mathrm{Hz}$

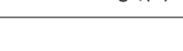

\section{0}

Frequency, $\mathrm{Hz}$

Excited Voltage,(V)

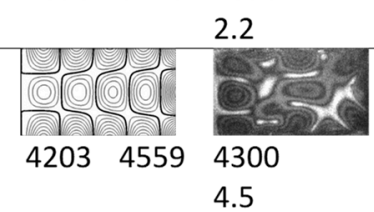

2.2

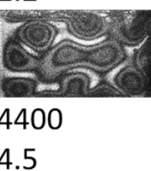

(b)

Figure 9. AF-ESPI and FEM results obtained from pumping element coupled with water in the (a)

upper and (b) lower piezoelectric plates.

In the air-coupled case, mode 3 did not appear in the AF-ESPI experiment below $6 \mathrm{kHz}$. In the water-coupled and glycerine-coupled cases, modes 6 and 8, and modes 3, 5, 6, and 8 did not appear, respectively. In the water-coupled case, mode 3 appeared in the AF-ESPI measurements; however, the mode shape was slightly altered due to the effects of density, sound velocity, and viscosity. Mode 3 cannot be measured by ESPI, as shown in Figure 8, which might be since there are two bimorphs vibrating in the small space (the distance between the two plates is very small), and the frequencies of mode 3 and 4 are relatively close. The mode shapes will be affected by both the interactions between 
two bimorphs and two modes. The similar reason might explain the results of modes $5,6,7$, and 8 in the water-coupled case, as shown in Figure 9. However, the modes with more vibration did not appear in glycerine-coupled case, as shown in Figure 10, since the fluid property of glycerine might have a more dramatic influence on the piezoelectric elements.

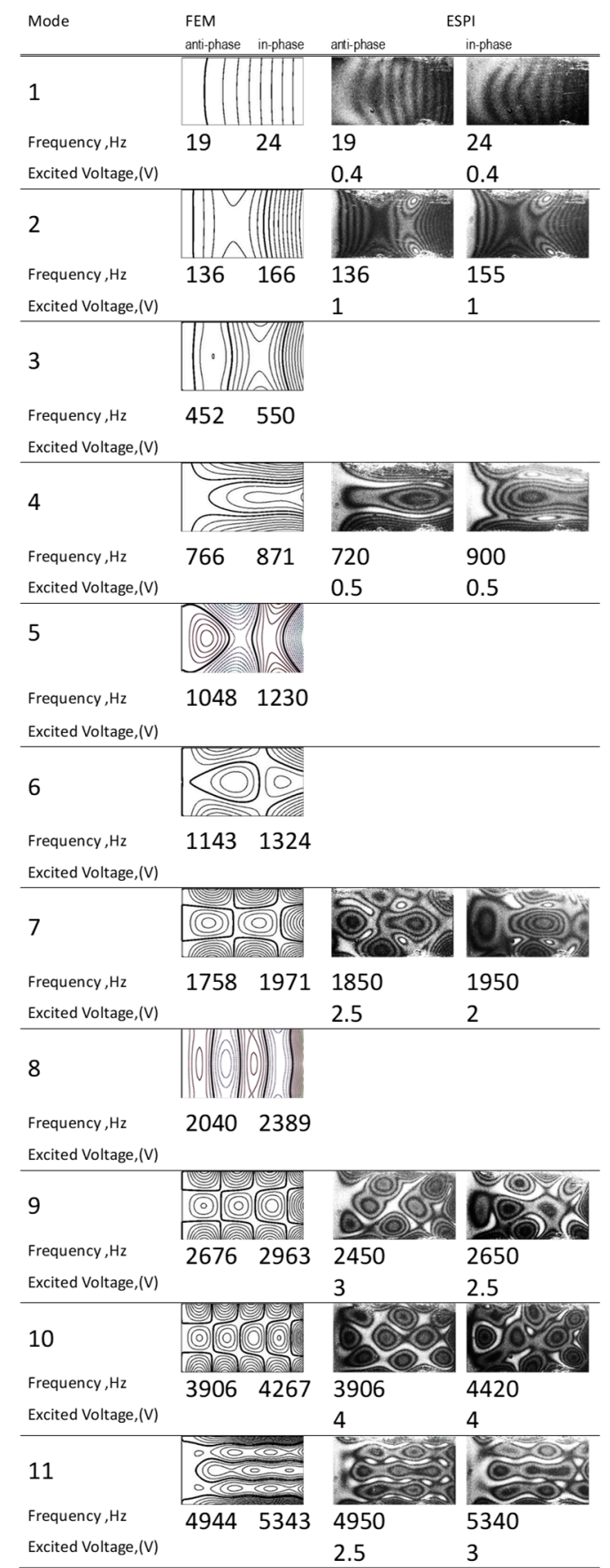

(a)

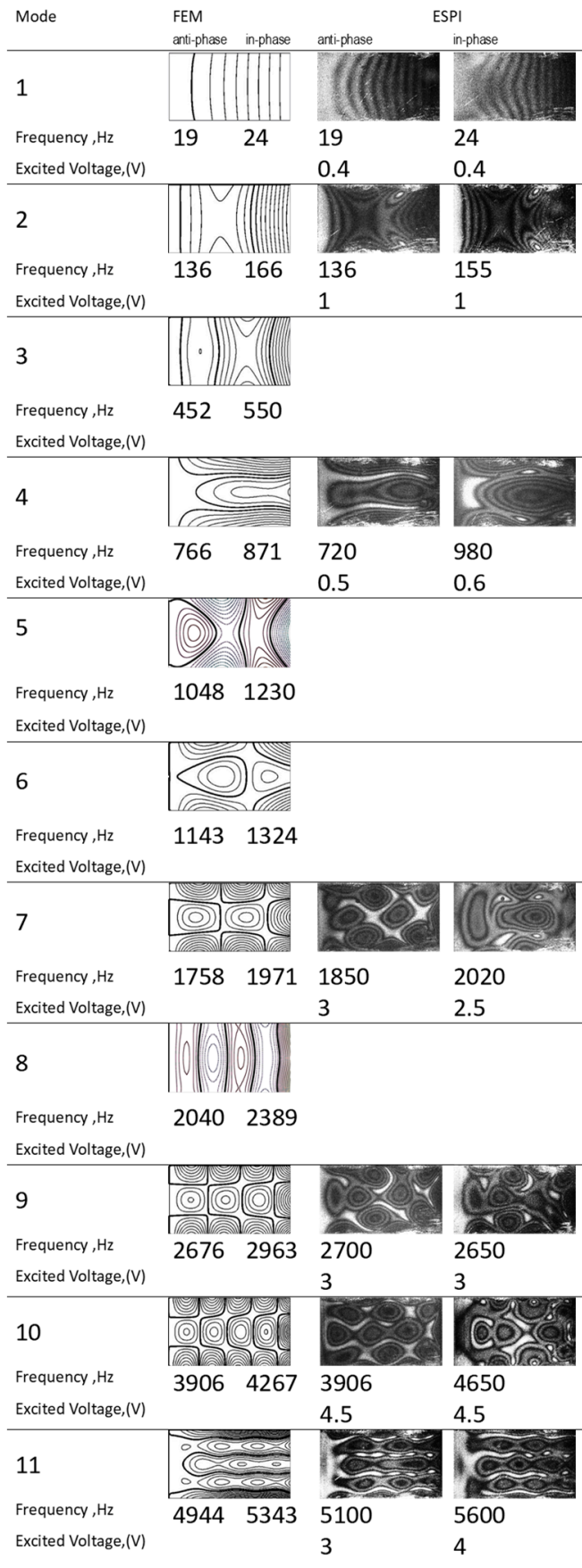

(b)

Figure 10. AF-ESPI and FEM results obtained from pumping element coupled with glycerin on the (a) upper and (b) lower piezoelectric plates.

Table 3 show that under air-coupled conditions, the resonance frequency and mode shape obtained in the AF-ESPI experiments were in good agreement with the FEM results, with a differences of less than $11 \%$. Under water-coupled and glycerine-coupled conditions, the differences between the experimental and numerical results were less pronounced at higher frequencies (Figures 8 and 9). The 
differences between the two (in terms of frequency) were less than $10 \%$ for all of the modes, as listed in Tables 4 and 5.

Table 3. Resonant frequencies of piezoelectric valveless micropumping element under air-coupled conditions. LDV: laser Doppler vibrometer.

\begin{tabular}{|c|c|c|c|c|c|c|c|c|}
\hline & Mode & FEM (Hz) & $\begin{array}{c}\text { AF-ESPI } \\
\text { (HZ) }\end{array}$ & $\begin{array}{c}\text { Difference } \\
(\%)\end{array}$ & LDV (Hz) & $\begin{array}{c}\text { Difference } \\
(\%)\end{array}$ & $\begin{array}{c}\text { Impedance } \\
\text { (Hz) }\end{array}$ & $\begin{array}{c}\text { Difference } \\
(\%)\end{array}$ \\
\hline \multirow{2}{*}{1} & Anti-phase & 79 & 84 & 6.33 & 80 & 1.27 & 79 & 0 \\
\hline & In-phase & 79 & 87 & 10.13 & 80 & 1.27 & & \\
\hline \multirow{2}{*}{2} & Anti-phase & 491 & 510 & 3.87 & 520 & 5.91 & 480 & -2.24 \\
\hline & In-phase & 492 & 519 & 5.49 & 500 & 1.63 & 470 & -4.47 \\
\hline \multirow{2}{*}{3} & Anti-phase & 1363 & & & 1380 & 1.25 & & \\
\hline & In-phase & 1366 & & & 1350 & -1.17 & & \\
\hline \multirow{2}{*}{4} & Anti-phase & 1636 & 1660 & 1.47 & 1780 & 8.80 & 1720 & 5.13 \\
\hline & In-phase & 1638 & 1770 & 8.06 & 1800 & 9.89 & 1790 & 9.28 \\
\hline \multirow{2}{*}{5} & Anti-phase & 2294 & 2410 & 5.06 & 2410 & 5.06 & 2425 & 0.62 \\
\hline & In-phase & 2296 & 2430 & 5.84 & 2410 & 4.97 & 2390 & -1.67 \\
\hline \multirow{2}{*}{6} & Anti-phase & 2780 & 2865 & 3.06 & 2810 & 1.08 & & \\
\hline & In-phase & 2783 & 2855 & 2.59 & & & & \\
\hline \multirow{2}{*}{7} & Anti-phase & 3443 & 3620 & 5.14 & 3280 & -4.73 & & \\
\hline & In-phase & 3446 & 3655 & 6.07 & 3270 & -5.11 & & \\
\hline \multirow{2}{*}{8} & Anti-phase & 4589 & 4555 & -0.74 & & & 4320 & -5.44 \\
\hline & In-phase & 4593 & 4560 & -0.72 & & & 4340 & -5.07 \\
\hline \multirow{2}{*}{9} & Anti-phase & 4957 & 5125 & 3.39 & & & 5010 & -2.29 \\
\hline & In-phase & 4960 & 5150 & 3.83 & & & 5050 & -1.98 \\
\hline
\end{tabular}

Table 4. Resonant frequencies of piezoelectric valveless micropumping element under water-coupled conditions.

\begin{tabular}{|c|c|c|c|c|c|c|c|c|}
\hline & Mode & FEM (Hz) & $\begin{array}{c}\text { AF-ESPI } \\
\text { (HZ) }\end{array}$ & $\begin{array}{l}\text { Difference } \\
(\%)\end{array}$ & LDV (Hz) & $\begin{array}{c}\text { Difference } \\
(\%)\end{array}$ & $\begin{array}{l}\text { Impedance } \\
(\mathrm{Hz})\end{array}$ & $\begin{array}{c}\text { Difference } \\
(\%)\end{array}$ \\
\hline \multirow{2}{*}{1} & Anti-phase & 21 & 20 & -4.76 & 20 & -4.76 & & \\
\hline & In-phase & 26 & 22 & -15.38 & 20 & -23.08 & & \\
\hline \multirow{2}{*}{2} & Anti-phase & 151 & 170 & 12.58 & 140 & -7.28 & 138 & -8.61 \\
\hline & In-phase & 183 & 175 & -4.37 & 150 & -18.03 & 150 & -18.03 \\
\hline \multirow{2}{*}{3} & Anti-phase & 499 & 490 & -1.80 & 420 & -15.83 & & \\
\hline & In-phase & 603 & 495 & -17.91 & 430 & -28.69 & 480 & -20.40 \\
\hline \multirow[b]{2}{*}{4} & Anti-phase & 834 & 800 & -4.08 & 890 & 6.71 & 945 & 13.31 \\
\hline & In-phase & 941 & 965 & 2.55 & 920 & -2.23 & 1110 & 17.96 \\
\hline \multirow{2}{*}{5} & Anti-phase & 1148 & 1200 & 4.53 & 1290 & 12.37 & 1345 & 17.16 \\
\hline & In-phase & 1332 & 1400 & 5.11 & 1380 & 3.60 & 1545 & 15.99 \\
\hline \multirow{2}{*}{6} & Anti-phase & 1245 & & & & & & \\
\hline & In-phase & 1436 & & & & & & \\
\hline \multirow{2}{*}{7} & Anti-phase & 1905 & 1870 & -1.84 & 2030 & 6.56 & 1950 & 2.36 \\
\hline & In-phase & 2120 & 2100 & -0.94 & 2060 & -2.83 & 2150 & 1.42 \\
\hline \multirow{2}{*}{8} & Anti-phase & 2227 & & & & & & \\
\hline & In-phase & 2586 & & & & & & \\
\hline \multirow{2}{*}{9} & Anti-phase & 2890 & 2890 & 0.00 & 2980 & 3.11 & 2810 & -2.77 \\
\hline & In-phase & 3176 & 3150 & -0.82 & 3150 & -0.82 & 3200 & 0.76 \\
\hline \multirow{2}{*}{10} & Anti-phase & 4203 & 4200 & -0.07 & & & & \\
\hline & In-phase & 4559 & 4500 & -1.29 & & & & \\
\hline
\end{tabular}


Table 5. Resonant frequencies of piezoelectric valveless micropumping element under glycerine-coupled conditions.

\begin{tabular}{|c|c|c|c|c|c|c|c|c|}
\hline & Mode & FEM (Hz) & $\begin{array}{c}\text { AF-ESPI } \\
\text { (HZ) }\end{array}$ & $\begin{array}{c}\text { Difference } \\
(\%)\end{array}$ & LDV (Hz) & $\begin{array}{c}\text { Difference } \\
(\%)\end{array}$ & $\begin{array}{l}\text { Impedance } \\
(\mathrm{Hz})\end{array}$ & $\begin{array}{c}\text { Difference } \\
(\%)\end{array}$ \\
\hline \multirow{2}{*}{1} & Anti-phase & 19 & 19 & 0 & 20 & 5.26 & & \\
\hline & In-phase & 24 & 24 & 0.00 & 30 & 25.00 & & \\
\hline \multirow{2}{*}{2} & Anti-phase & 136 & 136 & 0.00 & 140 & 2.94 & & \\
\hline & In-phase & 166 & 155 & -6.63 & 130 & -21.69 & & \\
\hline \multirow{2}{*}{3} & Anti-phase & 452 & & & 470 & 3.98 & & \\
\hline & In-phase & 550 & & & 620 & 12.73 & & \\
\hline \multirow{2}{*}{4} & Anti-phase & 766 & 720 & -6.01 & 730 & -4.70 & 775 & 1.17 \\
\hline & In-phase & 871 & 900 & 3.33 & 830 & -4.71 & 1000 & 14.81 \\
\hline \multirow{2}{*}{5} & Anti-phase & 1048 & & & 1050 & 0.19 & & \\
\hline & In-phase & 1230 & & & 1080 & -12.20 & & \\
\hline \multirow[b]{2}{*}{6} & Anti-phase & 1143 & & & 1150 & 0.61 & & \\
\hline & In-phase & 1324 & & & & & & \\
\hline \multirow{2}{*}{7} & Anti-phase & 1758 & 1850 & 5.23 & 1850 & 5.23 & & \\
\hline & In-phase & 1971 & 1950 & -1.07 & 1770 & -10.20 & & \\
\hline \multirow{2}{*}{8} & Anti-phase & 2040 & & & & & & \\
\hline & In-phase & 2389 & & & & & & \\
\hline \multirow[b]{2}{*}{9} & Anti-phase & 2676 & 2450 & -8.45 & 2450 & -8.45 & & \\
\hline & In-phase & 2963 & 2650 & -10.56 & 2650 & -10.56 & 3170 & 6.99 \\
\hline \multirow{2}{*}{10} & Anti-phase & 3906 & 3906 & 0.00 & & & & \\
\hline & In-phase & 4267 & 4420 & 3.59 & & & & \\
\hline \multirow[b]{2}{*}{11} & Anti-phase & 4944 & 4950 & 0.12 & & & 5200 & 5.18 \\
\hline & In-phase & 5343 & 5340 & -0.06 & & & & \\
\hline
\end{tabular}

Tables 3-5 show that under air-coupled conditions, the resonance frequency and mode shape obtained in the AF-ESPI experiments were in good agreement with the FEM results, with differences of less than $11 \%$. Under water-coupled and glycerine-coupled conditions, the differences between experimental and numerical results were less pronounced at higher frequencies (Figures 9 and 10). The differences between the two (in terms of frequency) were less than $10 \%$ for all of the modes except for the first three. The disturbances were more pronounced at lower frequencies due to the large vibration displacement.

It was easier to obtain AF-ESPI measurements from glycerol-coupled vibrations than from water-coupled vibrations thanks to the stability of the frequency response in higher viscosity liquids. Overall, in the AF-ESPI experiments, the degree to which the density, sound velocity, and viscosity coefficient influenced the vibration characteristics (particularly the mode shapes of the piezoelectric element) increased with an increase in frequency. At lower frequencies (below $2 \mathrm{kHz}$ ), the difference between AF-ESPI and numerical results (in terms of resonance frequency) were less pronounced under glycerine-coupled than air-coupled and water-coupled conditions.

Figures 11-13 respectively present frequency spectrum diagrams derived from LDV measurements of air-coupled, water-coupled, and glycerine-coupled vibrations. Tables $3-5$ respectively present the frequency values for air-coupled, water-coupled, and glycerine-coupled cases, as well as the degree to which they differed from the FEM results. It is clear that the differences were more pronounced under water-coupled and glycerine-coupled conditions than under air-coupled conditions. This may be because the laser light must penetrate the acrylic as well as the fluids in the LDV experiment, resulting in the consumption of some of the luminous energy, resulting in errors. The frequency difference between anti-phase and in-phase LDV measurements were more pronounced under water-coupled and glycerine-coupled conditions than under air-coupled conditions. The theoretical results for water-coupled and glycerine-coupled cases presented larger differences 
between anti-phase and in-phase modes (compared to the LDV experiment results). This may explain the discrepancies in the frequencies obtained using FEM and LDV.

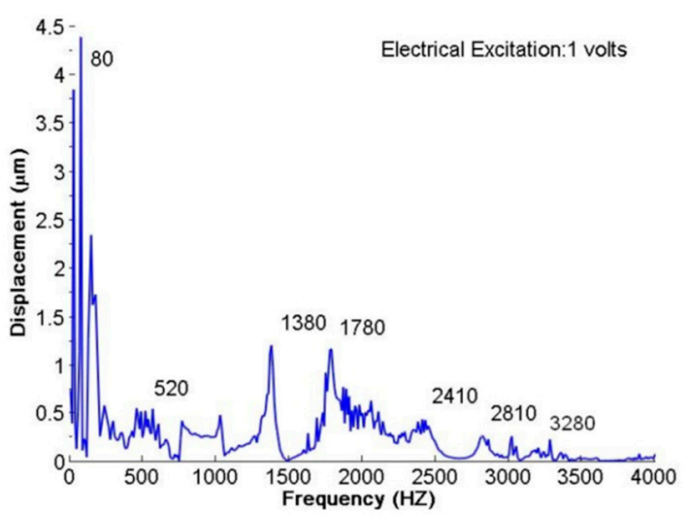

(a)

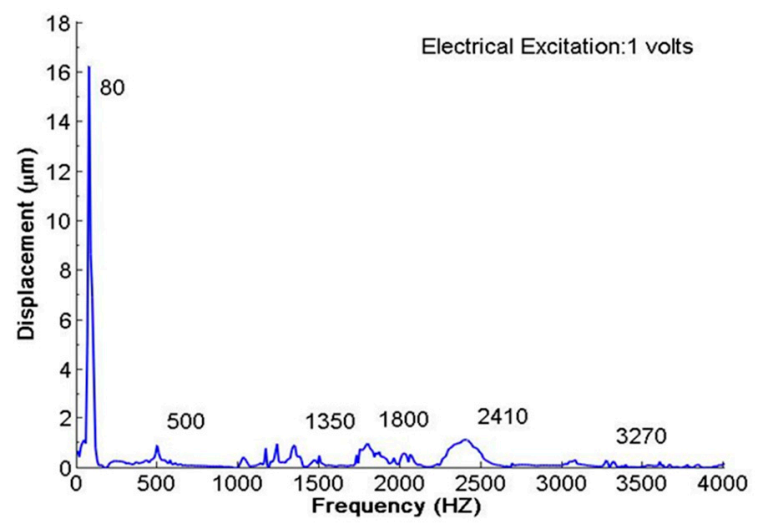

(b)

Figure 11. Laser Doppler vibrometer (LDV) displacement spectrum of air-coupled (a) anti-phase vibration and (b) in-phase vibration.

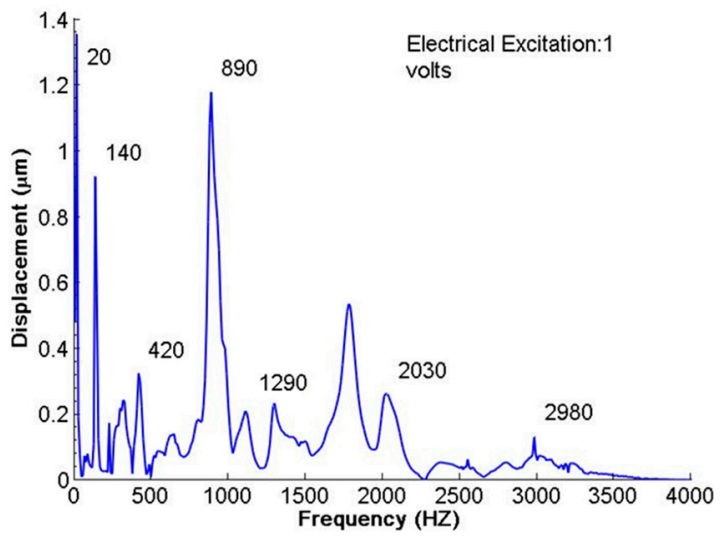

(a)

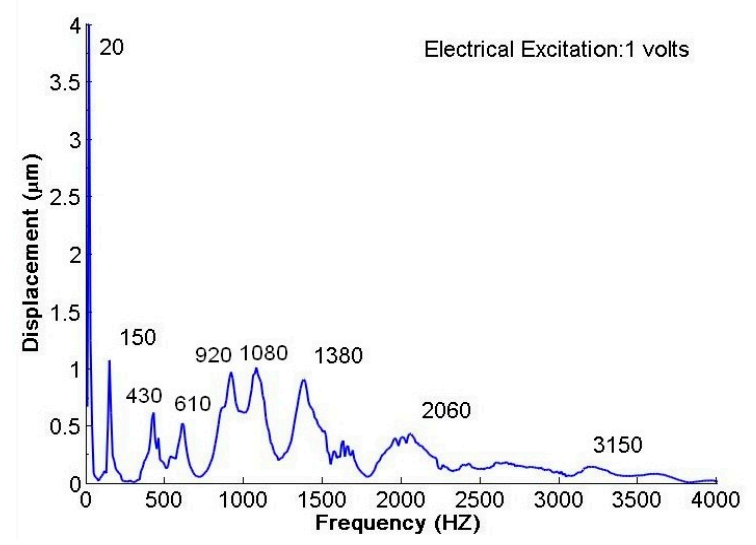

(b)

Figure 12. LDV displacement spectrum of water-coupled (a) anti-phase vibration and (b) in-phase vibration.

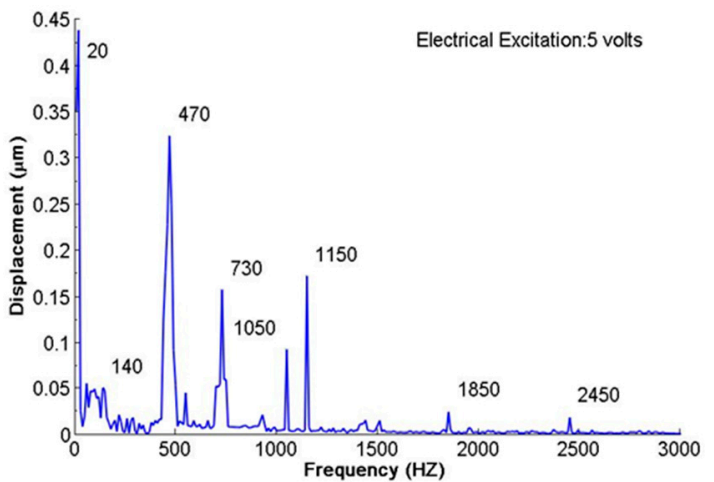

(a)

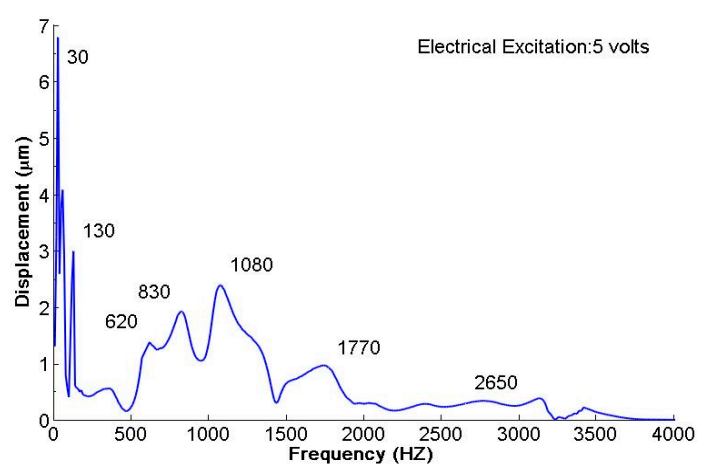

(b)

Figure 13. LDV displacement spectrum of glycerine-coupled (a) anti-phase vibration and (b) in-phase vibration.

Figures 14-16 respectively present the impedance variation curves (anti-phase and in-phase motion) obtained under air-coupled, water-coupled, and glycerine-coupled conditions. It is also 
indicated in the impedance variation curve, as shown in Figure 14, that the in-plane motion of mode 4 (1636 Hz in FEM) is relatively large compared to other modes; hence, the in-plane displacement of mode 4 may obstruct the reveal of mode 3 ( $1363 \mathrm{~Hz}$ in FEM). Tables 3-5 indicate the differences in frequency results obtained using FEM and LDV. Under water-coupled conditions, the differences were much larger in the low-frequency range due to disturbance from the water. Under glycerine-coupled conditions, some of the modes could not be measured due primarily to the relatively small range of in-plane motion.

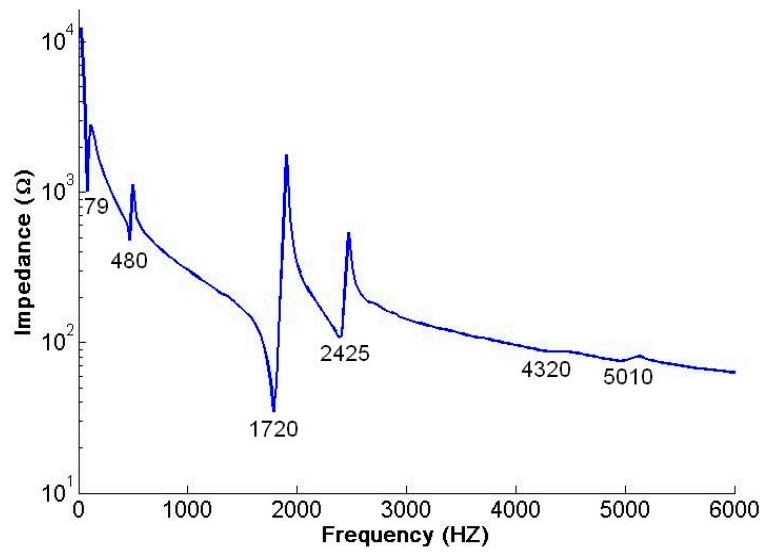

(a)

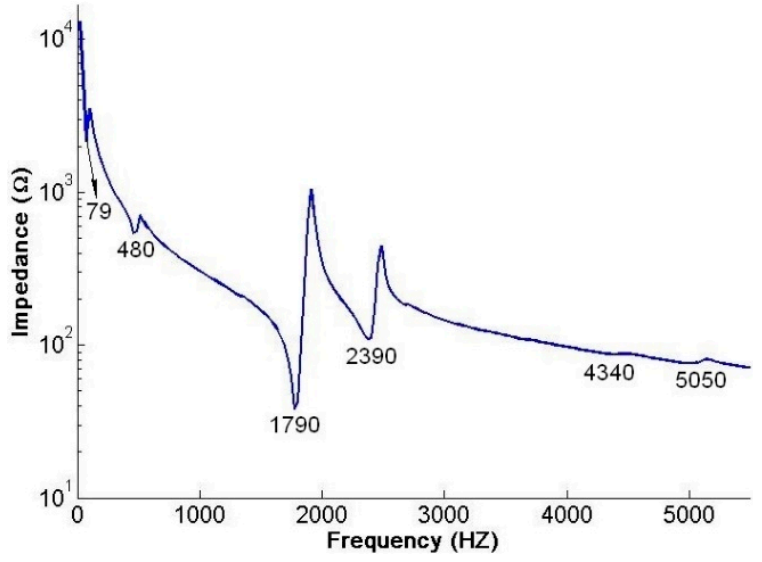

(b)

Figure 14. Impedance variation curve of air-coupled (a) anti-phase vibration and (b) in-phase vibration.

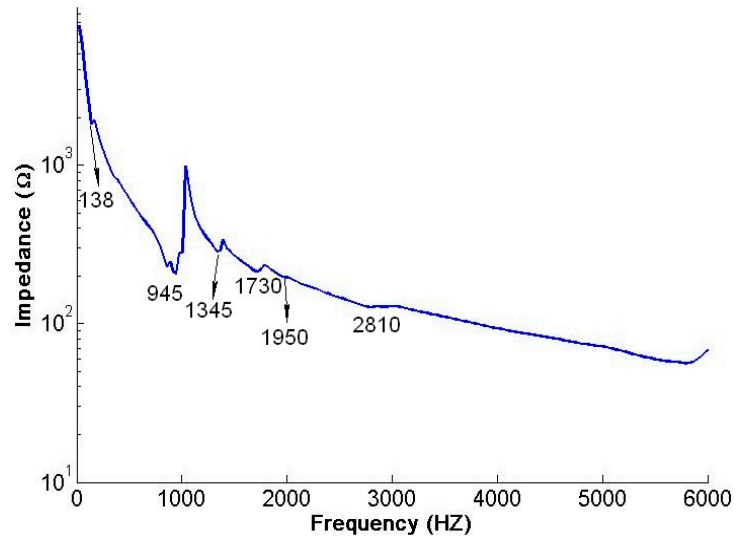

(a)

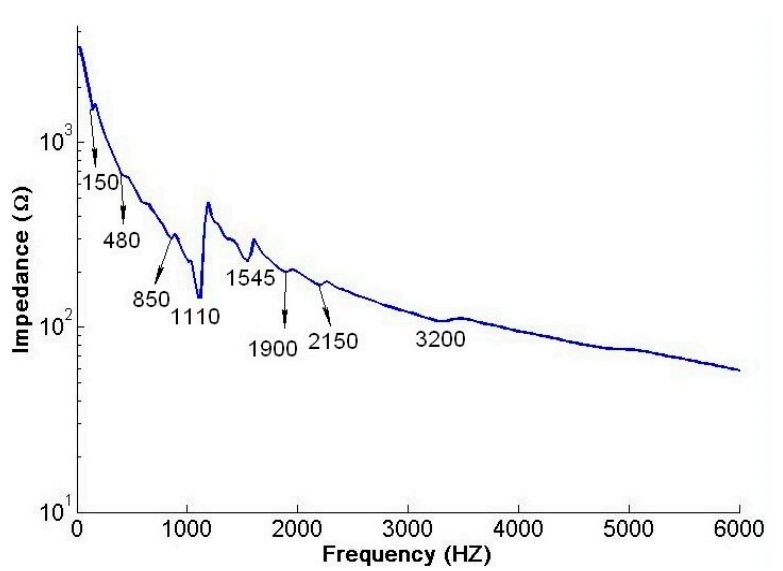

(b)

Figure 15. Impedance variation curve of water-coupled (a) anti-phase vibration and (b) in-phase vibration. 


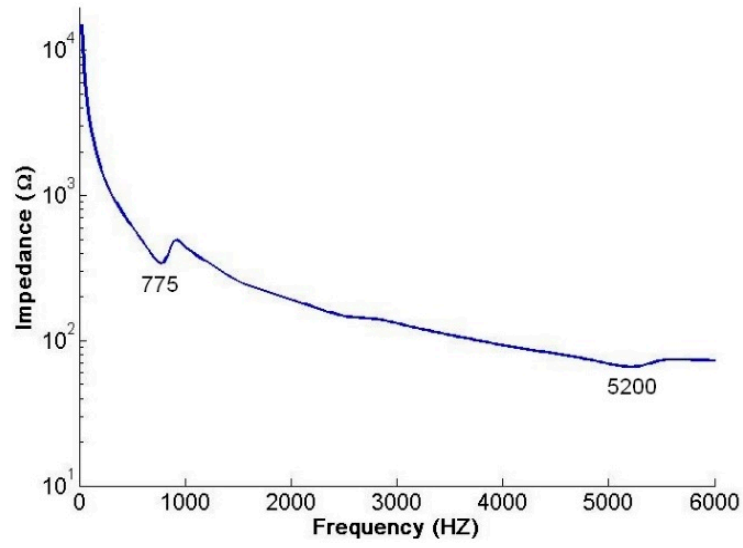

(a)

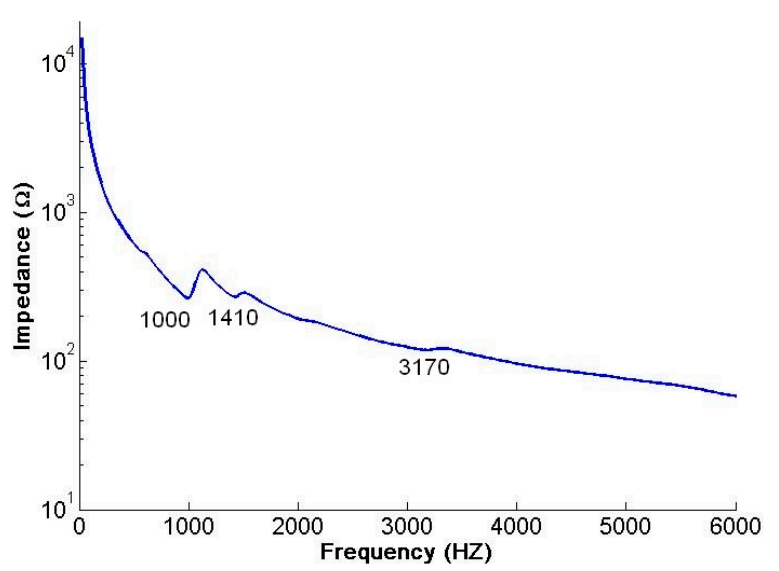

(b)

Figure 16. Impedance variation curve of glycerine-coupled (a) anti-phase vibration and (b) in-phase vibration.

Figure 17 present the air-coupled and water-coupled displacements caused by vibration at the tip of the free edge, as measured by LDV at various voltages. Note that only the first four modes are presented in this comparison. Displacement was shown to increase rapidly with voltage until eventually converging at a constant value, as indicated in the figures. This means that the input excitation voltage could be controlled to within a range that would prevent damage to the pumping element from excessive voltage. Under air-coupled conditions, the displacement of the first mode (approximately $50 \mu \mathrm{m}$ ) far exceeded that of the other three modes. In fact, 10 volts was sufficient to cause the piezoelectric bimorph to vibrate at its maximum displacement. Under water-coupled conditions, the maximum displacement at the mid-point along the free edge of the first mode was approximately $150 \mu \mathrm{m}$, and 10 volts was required to excite the bimorph to vibrate at the maximum displacements of each mode.

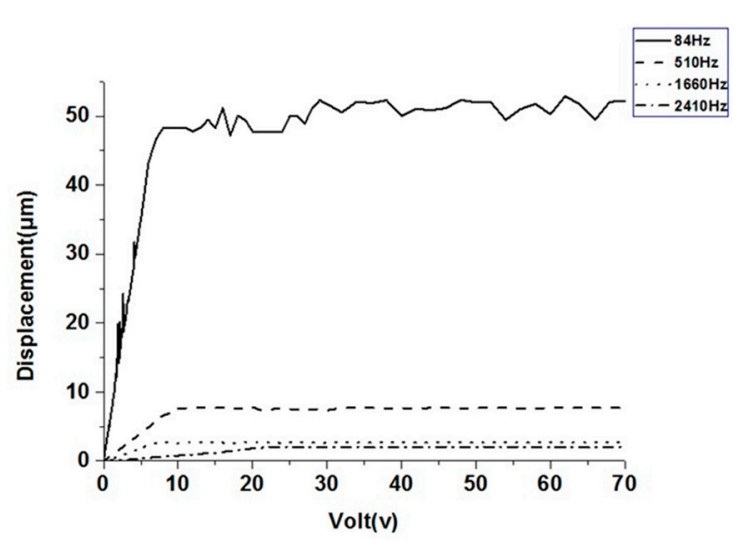

(a)

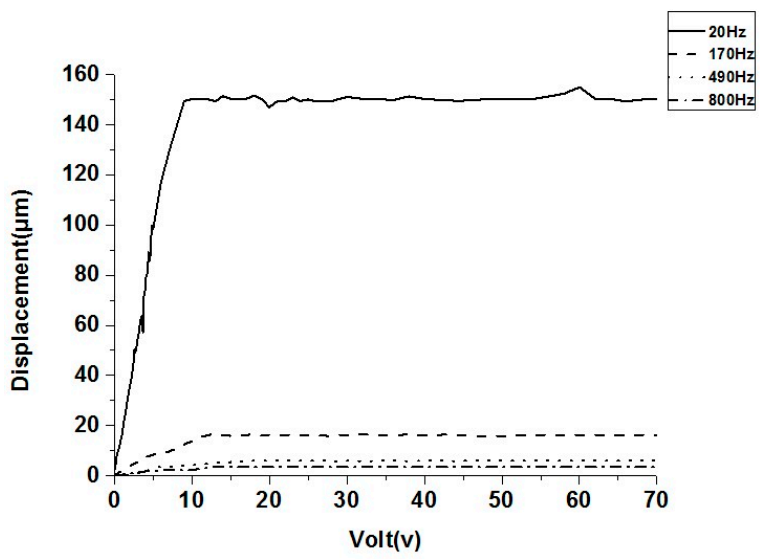

(b)

Figure 17. Variations in displacement with excitation voltage for first four modes under (a) air-coupled and (b) water-coupled conditions, as measured using LDV.

The results of the flow rate and the flow velocity of the pumping element for anti-phase and in-phase vibration are listed in Tables 6 and 7. As indicated in these data, both the gain of flow rate and the flow velocity increment are larger for anti-phase vibration than for in-phase vibration. For both average flow rate and velocity, the efficiency of low frequencies (first modes to third mode; that is, $20 \mathrm{~Hz}, 170 \mathrm{~Hz}$, and $490 \mathrm{~Hz}$ ) in anti-phase vibration is better because of the larger displacement, as shown in Tables 6 and 7. The gain of the second mode of anti-phase motion is relatively large compared 
to the other modes. The flow velocity of the pumping element with a single bimorph is also measured through the experiment, as shown in Table 8. More experimental and theoretical results about a single bimorph can be found in the published paper written about our previous study [25]. The optical experiment has much more difficulties for the dual bimorph, since one of the bimorphs is fixed in the lower position, and is obstructed by another bimorph. Comparing the results of these two studies, it is indicated that the mode shapes of a single bimorph and dual bimorph are similar, and there is a slight difference in the resonant frequencies between the single and dual bimorphs. The resonant frequencies decrease both in single and dual-bimorph piezoelectric pumping elements when the similar modes that were excited from air changed to water or glycerine. As shown in Figure 18, the pumping efficiency is presented related to increments of velocity from the values listed in Tables 7 and 8 . It is shown that the anti-phase vibration of the pumping element with the dual bimorph can clearly provide a better feature than that with a single bimorph due to the compression effect by two bimorphs, which deforms in opposite directions.

Table 6. The average flow rate and gain of the pumping element.

\begin{tabular}{|c|c|c|c|c|c|c|}
\hline $\begin{array}{l}\text { Frequency } \\
\text { Voltage }\end{array}$ & $1 \mathrm{~min}(\mu \mathrm{L} / \mathrm{s})$ & $2 \min (\mu \mathrm{L} / \mathrm{s})$ & $3 \min (\mu \mathrm{L} / \mathrm{s})$ & $\begin{array}{c}\text { Average Flow } \\
\text { Rate }(\mu \mathrm{L} / \mathrm{s})\end{array}$ & $\begin{array}{c}\text { Increment } \\
(\mu \mathrm{L} / \mathrm{s})\end{array}$ & Gain \\
\hline \multicolumn{7}{|c|}{ (a) anti-phase motion } \\
\hline $20 \mathrm{~Hz}$ & 3450 & 3458.3 & 3466.6 & 3458.3 & 75 & $2.22 \%$ \\
\hline $170 \mathrm{~Hz}$ & 3513.3 & 3531.7 & 3445 & 3496.7 & 113.4 & $3.35 \%$ \\
\hline $490 \mathrm{~Hz}$ & 3405 & 3473.3 & 3443.3 & 3440 & 56.7 & $1.68 \%$ \\
\hline $800 \mathrm{~Hz}$ & 3428.3 & 3433.3 & 3353.3 & 3405 & 21.7 & $0.64 \%$ \\
\hline $1250 \mathrm{~Hz}$ & 3421.6 & 3403.3 & 3438.3 & 3421.6 & 38.3 & $1.13 \%$ \\
\hline $1870 \mathrm{~Hz}$ & 3410 & 3320.3 & 3450 & 3393.4 & 10 & $0.3 \%$ \\
\hline $2890 \mathrm{~Hz}$ & 3401.7 & 3391.7 & 3381.7 & 3391.7 & 8.4 & $0.25 \%$ \\
\hline $4200 \mathrm{~Hz}$ & 3406.7 & 3373.3 & 3390 & 3385.3 & 2 & 0.06 \\
\hline \multicolumn{7}{|c|}{ (b) in-phase motion } \\
\hline $20 \mathrm{~Hz}$ & 3206.6 & 3178.3 & 3240 & 3226.7 & -156.6 & $-4.63 \%$ \\
\hline $170 \mathrm{~Hz}$ & 3405 & 3393.3 & 3443.3 & 3413.3 & 30 & $0.88 \%$ \\
\hline $490 \mathrm{~Hz}$ & 3338.3 & 3396.6 & 3220 & 3318.3 & -65 & $-1.92 \%$ \\
\hline
\end{tabular}

Excitation voltage for all frequencies: $9.0 \mathrm{Vpp}$; steady-state flow rate: $3383.3(\mu \mathrm{L} / \mathrm{s})$.

Table 7. The average flow velocity and gain of the pumping element.

\begin{tabular}{cccc}
\hline Frequency Voltage & Time (s) & $\begin{array}{c}\text { Average Velocity (cm/s) } \\
\text { Increment of Velocity (cm/s) }\end{array}$ \\
\hline $20 \mathrm{~Hz}$ & 5.21 & (a) anti-phase motion & 1.83 \\
$170 \mathrm{~Hz}$ & 4.95 & 11.99 & 2.47 \\
$490 \mathrm{~Hz}$ & 5.45 & 12.63 & 1.31 \\
$800 \mathrm{~Hz}$ & 5.83 & 11.47 & 0.56 \\
$1250 \mathrm{~Hz}$ & 5.63 & 10.72 & 0.94 \\
$1870 \mathrm{~Hz}$ & 5.8 & 11.10 & 0.62 \\
$289 \mathrm{~Hz}$ & 5.93 & 10.78 & 0.38 \\
$4200 \mathrm{~Hz}$ & 6.03 & 10.54 & 0.03 \\
\hline & & 10.19 & \\
$20 \mathrm{~Hz}$ & 5.75 & (b) in-phase motion & 0.71 \\
$170 \mathrm{~Hz}$ & 5.49 & 10.87 & 0.38 \\
$490 \mathrm{~Hz}$ & 5.93 & 11.38 & 0.54 \\
\hline
\end{tabular}

Excitation voltage for all frequencies: $9.0 \mathrm{Vpp}$; steady-state flow rate: $3383.3(\mu \mathrm{L} / \mathrm{s})$. 
Table 8. The average flow velocity and the velocity increment of the pump with a single bimorph.

\begin{tabular}{cccc}
\hline Frequency Voltage & Time (s) & Average Velocity $\mathbf{( c m} / \mathbf{s})$ & Increment of Velocity (cm/s) \\
\hline $20 \mathrm{~Hz}$ & 5.7 & 10.96 & 0.8 \\
$170 \mathrm{~Hz}$ & 5.13 & 12.18 & 2.02 \\
$490 \mathrm{~Hz}$ & 5.9 & 10.59 & 0.43 \\
\hline
\end{tabular}

Excitation voltage for all frequencies: $9.0 \mathrm{Vpp}$; steady-state flow rate: $3383.3(\mu \mathrm{L} / \mathrm{s})$.

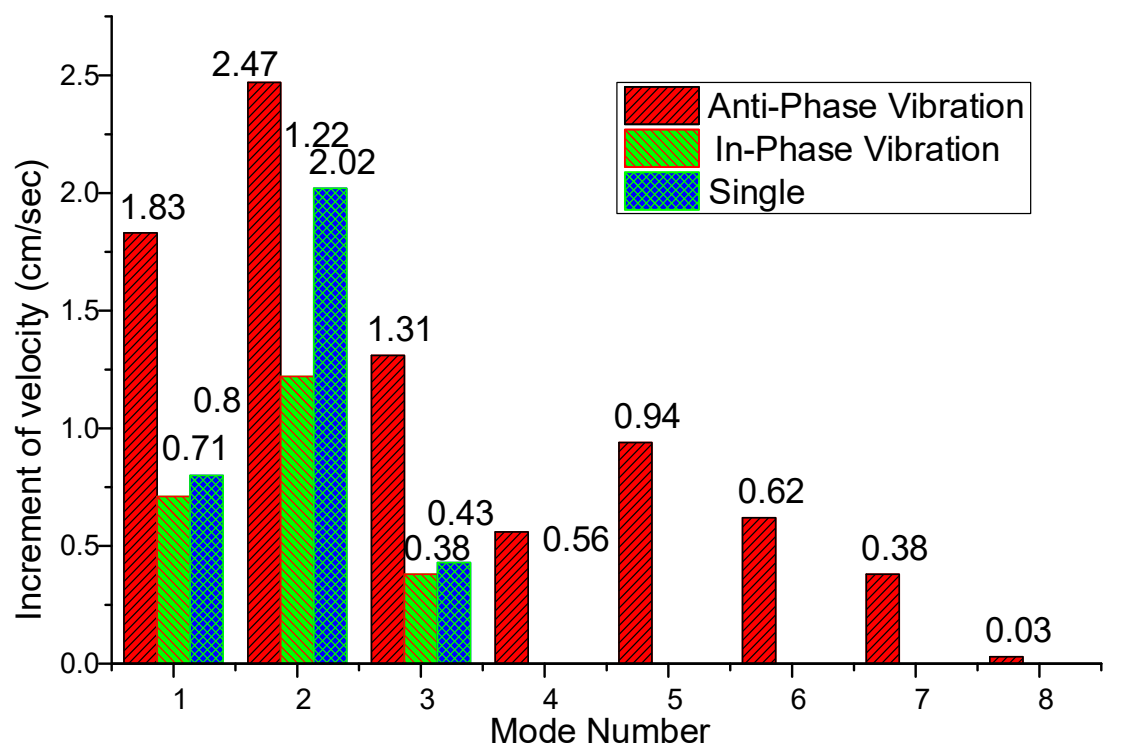

Figure 18. The increment of velocity for the pumping element in anti-phase vibration, in-phase vibration, and single plate.

\section{Conclusions}

Despite extensive research on the characteristics of piezoelectric micropumps, there has been relatively little work on the vibration of rectangular piezoelectric bimorphs coupled with fluids, and almost no work on dual-bimorph systems. In this paper, we present a novel piezoelectric pumping element. We conducted extensive analysis of the vibration characteristics under structure-liquid coupled conditions using full-field optical methods based on the AF-ESPI. This analysis provided clear fringes indicating the displacement and precise estimates of resonant frequencies. LDV and impedance analysis were also used to characterize the vibrations produced by the piezoelectric pumping element. Our experimental results are in good agreement with those obtained using finite element analysis in terms of mode shape and resonant frequencies.

The use of two piezoelectric bimorphs to drive the pumping element (rather than the single bimorph used in the previous designs) makes it possible to induce anti-phase as well as in-phase vibrations. Experimental and numerical results revealed that the resonant frequency of the anti-phase motion is lower than that of the in-phase motion. Coupling of the piezoelectric element with water or glycerine was far more pronounced than coupling with air due to the effects of density, acoustic velocity, and viscosity. In a comparison of experimental results and numerical findings, it was observed that the degree of deviation was far greater under water-coupled and glycerine-coupled conditions than under air-coupled conditions. The discrepancies in resonant frequency and mode shape between anti-phase and in-phase vibrations were also much more pronounced under fluid-coupled conditions than under air-coupled conditions. The influence of the vibration motion phase on both the flow rate and the flow velocity are also measured for the purpose of realizing the influences of different bimorph motion types on the efficiencies of the pumping element. It is indicated that the gain of flow rate obtained by the anti-phase motion of the dual-bimorph pumping element was larger than 
both those obtained by in-phase motion and by the single bimorph pumping element. For anti-phase vibration, the gain of flow rate for the first three modes were larger than those of higher frequencies. This research demonstrates the feasibility of dual-bimorph pump designs and provides an in-depth analysis of the vibration characteristics of the proposed piezoelectric pumping element.

Author Contributions: This study was initiated and designed by Y.-H.H., set-up experimental platform and conducted the experiments by K.-W.C. K.-W.C. were also responsible in numerical simulations. Y.-C.L. and Y.-H.H. wrote the paper and contributed in revising the paper. All authors contributed in analyzing the simulation and experimental results.

Funding: This research was funded by Ministry of Science and Technology (Republic of China) under Grant MOST 104-2628-E-011-002-MY3.

Acknowledgments: The authors gratefully acknowledge the financial support of this research by the Ministry of Science and Technology (Republic of China) under Grant MOST 104-2628-E-011-002-MY3.

Conflicts of Interest: The authors declare no conflict of interest.

\section{References}

1. Tiersten, H.F. Linear Piezoelectric Plate Vibrations; Plenum: New York, NY, USA, 1969.

2. Tzou, H.S. Piezoelectric Shells: Distributed Sensing and Control of Continua; Kluwer Academic Publishers: Dordrecht, The Netherlands, 1993.

3. Kunkel, H.A.; Locke, S.; Pikeroen, B. Finite-element analysis of vibrational modes in piezoelectric ceramics disks. IEEE Trans. Ultrason. Ferroelectr. Freq. Control 1990, 37, 316-328. [CrossRef] [PubMed]

4. Guo, N.; Cawley, P.; Hitchings, D. The finite element analysis of the vibration characteristics of piezoelectric discs. J. Sound Vibr. 1992, 159, 115-138. [CrossRef]

5. Ivina, N.F. Numerical analysis of the normal modes of circular piezoelectric plates of finite dimensions. Sov. Phys. Acoust. 1990, 35, 385-388.

6. Wu, J.; Lu, L. Liquid-solid coupled system of micropump. Acta Mech. Solida Sin. 2006, 19, 40-49. [CrossRef]

7. de Lima, C.R.; Vatanabe, S.L.; Choi, A.; Nakasone, P.H.; Pires, R.F.; Silva, C.N.E. A biomimetic piezoelectric pump: Computational and experimental characterization. Sens. Actuators A 2009, 152, 110-118. [CrossRef]

8. Zhou, Y.; Amirouche, F. Study of fluid damping effects on resonant frequency of an electromagnetically actuated valveless micropump. Int. J. Adv. Manuf. Technol. 2009, 45, 1187-1196. [CrossRef]

9. Hou, W.; Das, B.; Jiang, Y.; Quin, S.; Zheng, X.I.; Pi, X.; Yang, J.; Liu, H.G.; Zeng, J.; Zeng, Z.G. Simulation of the Diaphragm Properties of a PZT-based Valveless Micropump. In Proceedings of the 3rd IEEE International Conference on Nano/Micro Engineered and Molecular Systems, Sanya, China, 6-9 January 2008; pp. 449-452.

10. Ma, H.K.; Hou, B.R.; Wu, H.Y.; Lim, C.Y.; Gao, J.J.; Kou, M.C. Development and application of a diaphragm micro-pump with piezoelectric device. Microsyst. Technol. 2008, 14, 1001-1007. [CrossRef]

11. Ma, H.K.; Chen, B.R.; Gao, J.J.; Lim, C.Y. Development of an OAPCP-micropump liquid cooling system in a laptop. Int. Commun. Heat. Mass. Transf. 2009, 36, 225-232. [CrossRef]

12. Ma, H.K.; Su, H.C.; Wu, J.Y. Study of an innovative one-sided actuating piezoelectric valveless micropump with a secondary chamber. Sens. Actuators A 2001, 171, 297-305. [CrossRef]

13. Huang, C.H.; Ma, C.C. Vibration characteristics for piezoelectric cylinders using amplitude-fluctuation electronic speckle pattern interferometry. AIAA J. 1998, 36, 2262-2268. [CrossRef]

14. Huang, Y.; Zhang, J.H.; Hu, X.Q.; Xia, Q.X.; Huang, W.Q. Dynamics Analysis and Flow Rate Experiments on the Fish-Tailing Type of Valveless Piezoelectric Pump with RECTANGULAR vibrator. In Proceedings of the 2nd International Conference on Industrial Mechatronics and Automation, Wuhan, China, 30-31 May 2010; pp. 1127-1131.

15. Singh, S.; Kumar, N.; George, D.; Sen, A.K. Analytical modeling, simulations and experimental studies of a PZT actuated planar valveless PDMS micropump. Sens. Actuators A 2015, 225, 81-94. [CrossRef]

16. Ma, C.C.; Huang, C.H. The investigation of three-dimensional vibration for piezoelectric rectangular parallelepipeds using the AF-ESPI method. IEEE Trans. Ultrason. Ferroelectr. Freq. Control 2001, 48, 142-153. [PubMed]

17. Huang, C.H.; Lin, Y.C.; Ma, C.C. Theoretical analysis and experimental measurement for resonant vibration of piezoceramic circular plates. IEEE Trans. Ultrason. Ferroelectr. Freq. Control 2004, 51, 12-24. [CrossRef] [PubMed] 
18. Huang, C.H.; Ma, C.C.; Lin, Y.C. Theoretical, numerical, and experimental investigation on resonant vibrations of piezoceramic annular disks. IEEE Trans. Ultrason. Ferroelectr. Freq. Control 2005, 52, 1204-1216. [CrossRef] [PubMed]

19. Lin, Y.C.; Ma, C.C. Resonant vibration of piezoceramic plates in fluid. Interact. Multiscale Mech. 2008, 1, 177-190. [CrossRef]

20. Simulia. ABAQUS. Version 6.13 Documentation; Dassault Systémes Simulia Corp.: Providence, RI, USA, 2013.

21. Zhou, S.W.; Liang, C.; Rogers, C.A. An impedance-based system modeling approach for induced strain actuator-driven structures. J. Vib. Acoust. Trans. ASME 1996, 118, 323-331. [CrossRef]

22. Bhalla, S.; Soh, C.K. Structural health monitoring by piezo-impedance transducers I: Modelling. J. Aerosp. Eng. 2004, 17, 154-165. [CrossRef]

23. Bhalla, S.; Soh, C.K. Structural health monitoring by piezo-impedance transducers II: Applications. J. Aerosp. Eng. 2004, 17, 166-175. [CrossRef]

24. Huang, Y.H.; Ma, C.C. Experimental and numerical investigations of vibration characteristics for parallel-type and series-type triple-layered piezoceramic bimorphs. IEEE Trans. Ultrason. Ferroelectr. Freq. Control 2009, 56, 2598-2611. [CrossRef] [PubMed]

25. Huang, Y.H.; Hsu, H.T. Solid-liquid coupled vibration characteristics of piezoelectric hydroacoustic devices. Sens. Actuators A 2016, 238, 177-195. [CrossRef]

(C) 2019 by the authors. Licensee MDPI, Basel, Switzerland. This article is an open access article distributed under the terms and conditions of the Creative Commons Attribution (CC BY) license (http://creativecommons.org/licenses/by/4.0/). 